\title{
Ultraviolet A protective potential of plant extracts and phytochemicals
}

\author{
Denisa Skarupova, Jitka Vostalova, Alena Rajnochova Svobodova
}

\begin{abstract}
Chronic exposure to solar radiation is related to an increased incidence of various skin disorders, including premature skin aging and melanoma and non-melanoma skin cancers. Ultraviolet (UV) photons in particular are responsible for skin damage. Solar UV photons mainly belong to UVA wavebands, however UVA radiation has been mostly ignored for a long time. At the cellular level, UVA photons mainly provoke indirect oxidative damage to biomolecules via the massive generation of unstable and highly reactive compounds. Human skin has several effective mechanisms that forestall, repair and eliminate damage caused by solar radiation. Regardless, some damage persists and can accumulate with chronic exposure. Therefore, conscious protection against solar radiation (UVB+UVA) is necessary. Besides traditional types of photoprotection such as sunscreen use, new strategies are being searched for and developed. One very popular protective strategy is the application of phytochemicals as active ingredients of photoprotection preparations instead of synthetic chemicals. Phytochemicals usually possess additional biological activities besides absorbing the energy of photons, and those properties (e.g. antioxidant, anti-inflammatory) magnify the protective potential of phytochemicals and extracts. Therefore, compounds of natural origin are in the interest of researchers as well as developers.

In this review, only studies on UVA protection with well-documented experimental conditions are summarized. This article includes 17 well standardized plant extracts (Camellia sinensis (L.) Kuntze, Silybum marianum L. Gaertn., Punica granatum L., Polypodium aureum L., Vaccinium myrtillus L., Lonicera caerulea L., Thymus vulgaris L., Opuntia ficus-indica (L.) Mill., Morinda citrifolia L., Aloe vera (L.) Burm.f., Oenothera paradoxa Hudziok, Galinsoga parviflora Cav., Galinsoga quadriradiata Ruiz et Pavón, Hippophae rhamnoides L., Cola acuminata Schott \& Endl., Theobroma cacao L. and Amaranthus cruentus L.) and 26 phytochemicals.
\end{abstract}

Key words: UVA radiation, ROS, skin, photoprotection, natural compounds, extract

Received: August 9, 2019; Revised: December 4, 2019; Accepted: March 4, 2020; Available online: March 17, 2020 https://doi.org/10.5507/bp.2020.010

(c) 2020 The Authors; https://creativecommons.org/licenses/by/4.0/

Department of Medical Chemistry and Biochemistry, Faculty of Medicine and Dentistry, Palacky University, Hnevotinska 3, 775 15 Olomouc, Czech Republic

Corresponding author: Alena Rajnochova Svobodova, e-mail:alf.svoboda@seznam.cz

\section{INTRODUCTION}

Solar radiation is electromagnetic radiation produced by the Sun, ranging from about 0.25 to $4.5 \mu \mathrm{m}$ in wavelength including infrared, visible, and ultraviolet (UV) light. Sunlight is an inseparable part of human life. It is a key factor in plant photosynthesis as well as in vitamin $\mathrm{D}_{3}$ synthesis in human skin. However, it also has several negative effects on human health. The harmful effects are mainly associated with the UV waveband. The amount of UV radiation reaching the earth's surface has been increasing over the last few decades. Human lifestyle has changed as well, especially time spent in outdoor activities (sports, sunbathing, or sunbed tanning). As a result, our body, particularly our skin, receives higher doses of UV radiation than before, which is linked with a more frequent incidence of various acute and chronic detrimental cutaneous effects, including skin cancer. Originally, it was thought that only the high energetic photons of the UVB waveband (280-315 nm) are responsible for the adverse effects of solar light. As a result, the photoprotection of human skin was focused on protection against
UVB rays for many years. More recently, an increasing number of independent studies indicated that UVA radiation (315-400 nm) also induces damage to skin cells. It is therefore essential to have effective protection against UVA radiation as well ${ }^{1}$. This review summarises studies on pure compounds or extracts derived from natural sources that have demonstrated protective potential against UVA radiation in skin cells and/or tissue.

\section{UVA RADIATION}

The sun is primarily a UVA source, as UVA amounts to over $90 \%$ of the UV radiation reaching the earth's surface. UVA radiation is further subdivided into UVA1 (340-400 $\mathrm{nm})$ and UVA2 (315-340 nm). UVA photons penetrate deep into the epidermis and dermis of the skin. About $80 \%$ of UVA radiation reaches the dermo-epidermal junction and penetrates into the papillary dermis. In this way UVA may affect most of the skin cells, especially keratinocytes, melanocytes, fibroblasts and endothelial cells in blood vessels. UVA-induced responses in cells occur 
predominantly via the activation of oxidative processes initiated by endogenous photosensitization. UVA photons primarily initialize the production of reactive oxygen and nitrogen species (ROS, RNS) through interacting with endogenous chromophores (photosensitizers). In particular superoxide and singlet oxygen is produced. The latter can be dismutated to hydrogen peroxide, which in turn can produce hydroxyl radicals after reacting with metal ions. RNS include nitric oxide and peroxynitrite. The cellular photosensitizers have not been fully characterized, but candidates include bases of nucleic acids, aromatic amino acids, NAD(P)H, heme, quinones, flavins, porphyrins, 7-dehydrocholesterol, eumelanin, urocanic acid etc. ROS/ RNS can oxidize cellular proteins, lipids, and saccharides. The oxidized products of lipids include alkoxyl radicals, aldehydes, alkanes, lipid (hydro)peroxides and epoxides. These highly reactive compounds may further provoke oxidative damage to biomolecules. As for proteins, all amino acid side chains can be oxidized to generate protein carbonyl groups. The sulphydryl groups of methionine and cysteine are particularly susceptible to oxidation. Several DNA replication and repair proteins have been shown to be targets of reactive compounds that arise upon UVA exposure. ROS/RNS can also induce various types of oxidative DNA lesions such as single-strand breaks and DNA-protein crosslinks, but mainly altered DNA bases. Due to their lowest ionisation potential, guanine bases are the most susceptible to oxidation, and 8-hydroxydeoxyguanine $(8-\mathrm{OH}-\mathrm{dG})$ is a characteristic oxidative product. UVA was also found to produce a significant yield of cyclobutane-pyrimidine dimers (CPD). ROS/RNS, unstable oxidised products as well as DNA lesions can affect various cellular pathways and the expression of numerous genes such as inflammatory cytokines, transcription factors, matrix metalloproteinases (MMP), mitogen-activated protein kinases (MAPK), or pro- and anti-apoptotic genes. These signalling molecules initiate the development of pathological changes in skin tissue such as altered epidermal cell proliferation and differentiation, decrease in collagen synthesis, upregulation of extracellular matrix-degrading enzymes such as collagenase (MMP-1), stromelysin (MMP-3), gelatinase (MMP-9) or elastase. On the other hand, increased levels of oxidatively modified molecules stimulate the activity, activation or synthesis of protective molecules such as nuclear factor erythroid-2 related factor 2 (Nrf2), phase 2 detoxifying enzymes (e.g., glutathione $S$-transferase (GST), NADPH quinone oxidoreductase-1 (NQO1), $\gamma$-glutamate-L-cysteine ligase $(\gamma$-GCL) or heme oxygenase-1 (HO-1)), DNA reparation enzymes and others that aim to suppress the adverse biological effects of UVA radiation. However, intensive exposure to UVA light can exceed protective mechanisms, and chronic exposure to UVA radiation leads to the step-by-step accumulation of oxidatively modified molecules and loss of the vascular network, all of which may result in skin inflammation, immunosuppression, photodermatosis, premature skin aging (photoaging) and/or carcinogenesis ${ }^{1-4}$ (Fig. 1).

\section{Solar UV radiation}

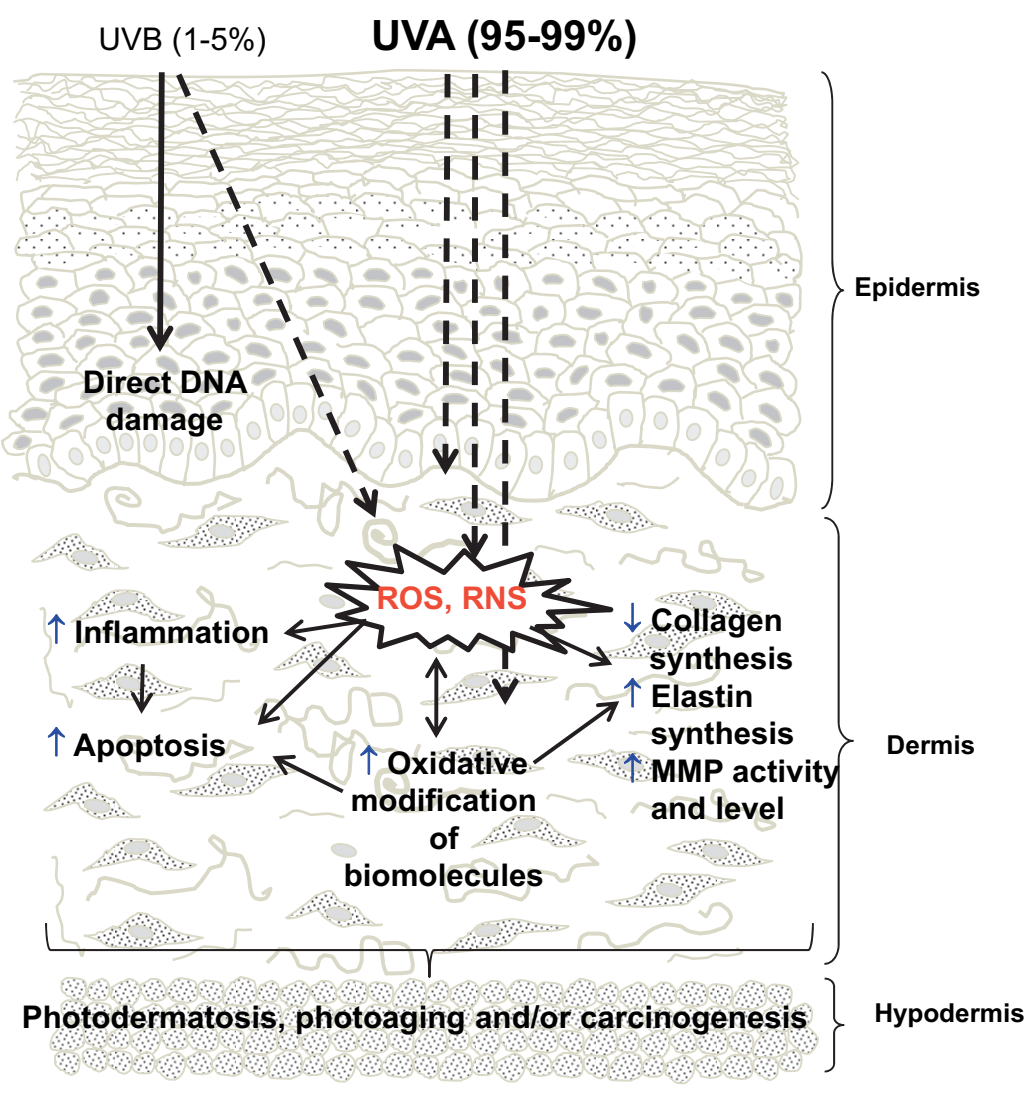

Fig. 1. Effects of solar UV radiation on skin tissue. 


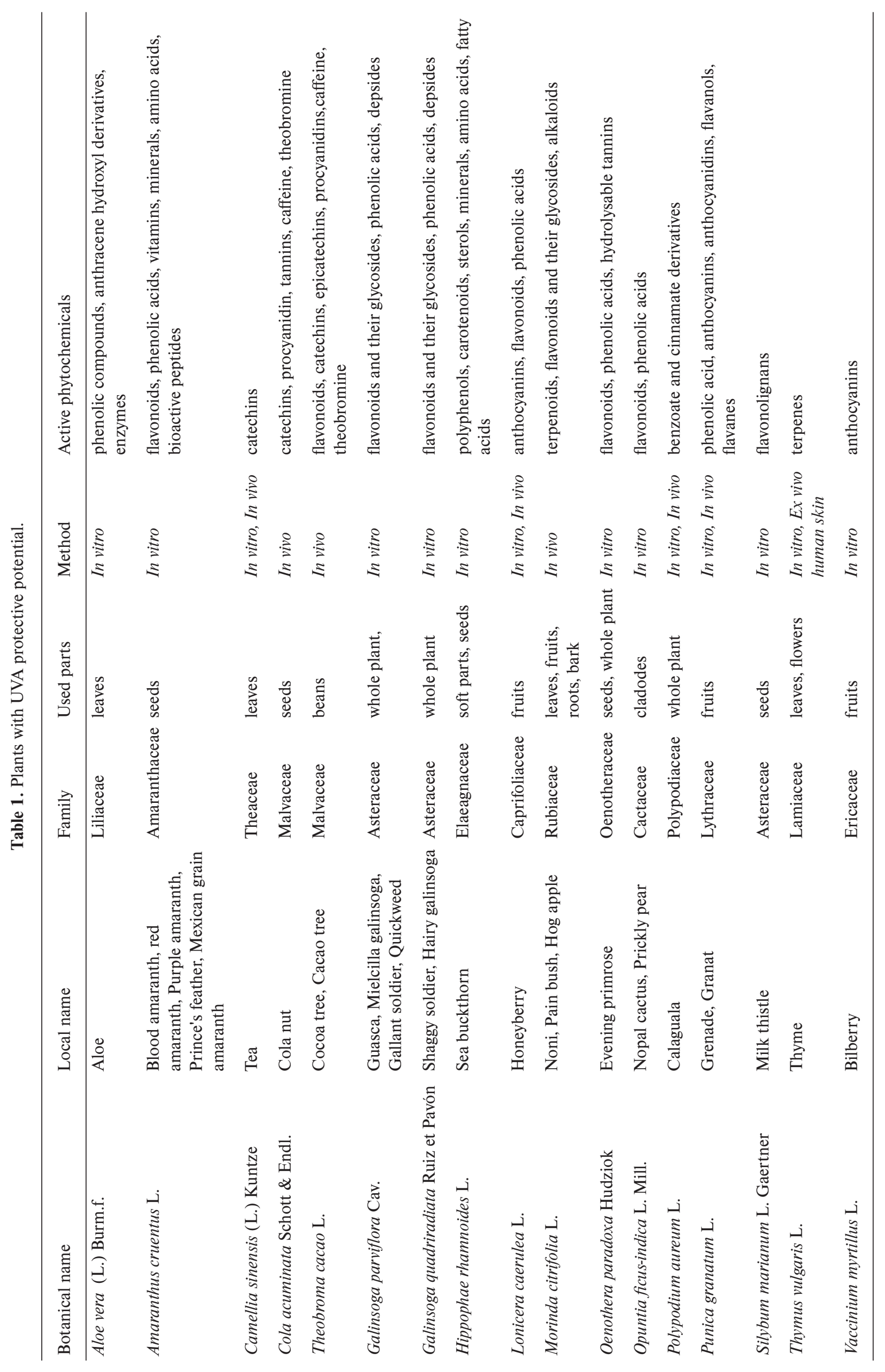




\section{PLANT EXTRACTS AND PHYTOCHEMICALS WITH UVA PROTECTIVE POTENTIAL}

In response to the environment, many living organisms produce specific secondary metabolites that help them to grow successfully and continue their lineage. Some of these secondary metabolites have been found to provide UV protective properties, even though they probably have other physiological roles. These compounds with UV protective activities are widely distributed across the microbial, plant and animal kingdoms, and share some common chemical features ${ }^{5}$. They act as UV absorbers (blockers) including phenolic acids, flavonoids, non-flavonoids and terpenoids. These compounds can prevent or diminish the penetration of UV photons into the skin tissue, resulting in a reduction in the interaction of UV photons with endogenous chromophores, oxidative stress, DNA damage and inflammation. Besides these abilities, some phytochemicals were also found to modulate multiple signalling pathways ${ }^{6}$. Therefore, these naturally occurring compounds have gained considerable attention for their potential use as effective agents for preventing or reducing the UV-induced oxidative modification of biomolecules and subsequent events involved in skin pathology such as photoaging and skin cancer. This review makes an attempt to summarize the results of research on the protective properties of various phytochemicals or extracts, with the focus on UVA radiation. Only papers with well characterized phytochemicals or extracts and experimental conditions were selected for the review.

\section{Plant extracts \\ Camellia sinensis}

Tea (Camellia sinensis (L.) Kuntze) is a plant of the Theaceae family. A hot water infusion of tea leaves is one of the most consumed beverages in the world. Tea is divided into subtypes based on its processing. White tea consists of minimally processed young leaves. Green tea originates from minimally processed mature leaves, while oolong tea is semi-fermented and black tea is fully fermented. Green tea is an abundant source of polyphenols known as catechins. They generally account for $30-42 \%$ of the dry solids in brewed green tea. The major catechins found in green tea include (-)-epicatechin (EC), (-)-epicatechin-3-gallate (ECG), (-)-epigallocatechin (EGC), and (-)-epigallocatechin-3-gallate (EGCG). EGCG is the most abundant and forms $50-80 \%$ of the total amount of catechins. The polyphenol content of black tea is different from that of green tea due to the degree of oxidation during processing. It mainly contains the following polyphenols: thearubigins, theaflavins, flavonols, and catechins. Among the tea polyphenols, EGCG has been shown to be the most effective chemoprotective agent against cutaneous inflammatory or carcinogenic responses. The potential of tea polyphenols against UVBinduced DNA damage, inflammation, oxidative stress, alterations in cell signalling pathways, and epigenetics changes that play a pivotal role in photocarcinogenesis are summarized in a recent review ${ }^{7}$ EGCG is also the most commonly evaluated green tea component in terms of UVA protection. The EGCG pre-treatment of a spontaneously transformed aneuploid immortal human skin keratinocyte cell line (HaCaT) reduced UVA-induced ROS generation, DNA single-strand breaks and alkali-labile site formation, hypoxanthine-guanine phosphoribosyl transferase (HPRT) mutant frequency ${ }^{8}$ as well as nuclear factor kappa B (NF-кB) nuclear translocation and interleukin-6 (IL-6) secretion'. EGCG protected normal human dermal fibroblasts (NHDF) against UVA damage by downregulating the transcription activity of Jun protein and the mRNA and protein level of MMP-1 (ref. ${ }^{10}$ ). The treatment of human infant skin fibroblasts with EGCG decreased beta-galactosidase positive cell number and the frequency of the HPRT gene mutation in UVA-irradiated cells ${ }^{11}$. EGCG inhibited the UVA-induced cell death of ARPE19 adult human retinal pigment epithelial cells. In addition, EGCG suppressed intracellular hydrogen peroxide generation, extracellular signal-regulated kinases (ERK), c-Jun N-terminal kinase 1/2 (JNK) and p38 kinase activation as well as cyclooxygenase 2 (COX-2) protein expression in the irradiated cells ${ }^{12}$. The pre-treatment of male Wistar albino rats with EGCG in a hydrophilic ointment resulted in a significant reduction in sunburn cell count and degeneration and disintegration in the dermo-epidermal junction in UVA-exposed animals ${ }^{13}$. Pre-treatment with EGCG reduced wrinkles in the dorsal trunk and also prevented the reduction of collagen synthesis in the skin of UVAirradiated hairless mice ${ }^{14}$.

The UVA protection of less abundant green tea polyphenols was also evaluated in several in vitro studies. The pre-treatment of a FEK4 human skin fibroblast cell line with EGC caused a strong reduction in UVA-induced HO1, but MMP-1 and COX-2 mRNA expression was stimulated. On the other hand, in a KB human oral carcinoma cell line, UVA-stimulated COX-2 mRNA was strongly reduced with EGC (ref. ${ }^{15}$ ). In UVA-irradiated HaCaT, EGC pretreatment increased viability, and reduced hydrogen peroxide production and ERK activation ${ }^{16}$. The pre-treatment of FEK4 fibroblasts with EC and its metabolite 3'-O-methyl epicatechin (MeOEC) increased cell viability and reduced the number of necrotic cells. EC further prevented the suppression of HO-1 transcription ${ }^{17}$. EC and MeOEC also suppressed the UVA-mediated release of chelatable iron and the mRNA expression of MMP-1 in FEK4 fibroblasts. EC treatment also protected the lysosomal membrane against UVA-induced damage ${ }^{18}$. In both studies ${ }^{17,18}$, EC was more effective than its metabolite. The application of a nano-gel formulation of catechin to the skin of male Wistar rats reduced the oxidative stress induced by UVA, most significantly improving the level of cutaneous antioxidant enzymes (superoxide dismutase (SOD), glutathione peroxidase (GPX) and catalase (CAT)), and reducing the level of thiobarbituric acid reactive substances (TBARS) $\left(\right.$ ref. $\left.^{19}\right)$.

\section{Silybum marianum}

Silymarin (SM) is a standardized polyphenol fraction from the seeds of Silybum marianum L. Gaertner (syn. Carduus marianus L. or milk thistle) from the Asteraceae family. S. marianum is one of the oldest known plants, and 
has been widely used in traditional European medicine since ancient times. The plant as well as SM is rich in polyphenols. SM contains approximately $70-80 \%$ flavonolignans, and $20-30 \%$ is a chemically undefined fraction, mostly comprised of polymeric and oxidised polyphenolic compounds. The main polyphenolic component of SM is the flavonolignan silybin (SB). Other less abundant components are the flavonolignans isosilybin (ISB), silychristin (SC), silydianin (SD) and the flavonoid taxifolin. A minor component but with a significant biological potential is the flavonolignan 2,3-dehydrosilybin (DHSB) $\left(\right.$ ref. $\left.{ }^{20}\right)$. SM has been primarily used in the treatment of liver disorders including hepatitis, alcoholic liver diseases, and cirrhosis, and is also useful against toxin-induced liver toxicity. Laboratory studies suggest that there is no significant difference between SM and its major component SB in terms of biological activities. Research results showed antioxidant activity, modulation of the immune system and various signalling pathways for both SM and SB $\left(\right.$ ref. $^{21}$ ). Several reports documented the ability of SM and SB to reduce chemically- and UVB-stimulated skin damage, including carcinogenesis ${ }^{21,22}$.

The pre-treatment of NHDF with SM and SB resulted in a reduction in UVA-stimulated ROS and the production of DNA single-strand breaks, as well as in the prevention of glutathione (GSH) depletion, a decrease in the activation of caspase- 3 and MMP-1 protein. SM also moderately increased HO-1 and reduced the level of heat shock protein 70 (HSP 70) (ref. ${ }^{23}$ ). Also, less abundant flavonolignans in silymarin, ISB, SD, SC and DHSB demonstrated the ability to reduce UVA-induced damage in NHDF ( ref. $^{24}$ ). The post-treatment of UVA-irradiated $\mathrm{HaCaT}$ with SM (ref. ${ }^{25}$ ) and SB (ref. ${ }^{26}$ ) resulted in the diminution of UVA-caused ROS production, caspase-3 activation, GSH and ATP depletion as well as lipid peroxidation and the formation of DNA single-strand breaks.

However, besides many reports on the photoprotection of SM and its main congener SB, there are also controversial studies demonstrating an in vitro phototoxic activity of SM (ref. ${ }^{27}$ ) and SB (ref. ${ }^{28}$ ). The phototoxic potential of the minor flavonolignan DHSB, a dihydroxy derivative of $\mathrm{SB}$, was recently also described in skin cells ${ }^{24,29}$. DHSB is very potent antioxidant with a moiety that is structurally similar to quercetin, which has also been shown to be a phototoxic compound. The phototoxic potential of DHSB and perhaps SM needs be confirmed in vivo or in clinical trials.

\section{Punica granatum}

Pomegranate also known as grenade, granats, and punica apple, is a fruit of the Punica granatum L. tree from the family Lythraceae. It is indigenous to the Himalayas in northern India through to Iran, parts of Southeast Asia, the East Indies, and tropical Africa, and grows in almost all parts of the Mediterranean region. Pomegranate is rich in phenolic acids, flavanols, flavones, flavonones, anthocyanidins, and anthocyanins ${ }^{30}$. The fruit and its pericarp contain two main polyphenol groups, anthocyanins (cyanidin and delphinidin) and hydrolysable tannins (punicalin, pedunculagin, punicalagin, and gallagic and el- lagic esters of glucose). Pomegranate has been recognized since antiquity for its healing properties. Pomegranate fruit extract exhibits antioxidant and anti-inflammatory properties. Many in vitro and in vivo studies demonstrated a photoprotective effect of pomegranate against UVB radiation $^{22}$.

UVA-induced ROS generation and the cell death of SKU-1064 human skin fibroblasts were reduced by pomegranate extract pre-treatment in a dose-dependent fashion $^{31}$. A concentrated pomegranate solution decreased UVA-induced MMP-1 activity in neonatal NHDF (ref. ${ }^{32}$ ). The pre-treatment of normal human epidermal keratinocytes (NHEK) with pomegranate fruit extract resulted in a dose-dependent inhibition of the UVA-mediated phosphorylation of signal transducer and activator of transcription 3 at Tyr705, AKT at Ser473 and ERK1/2. The extract also inhibited the UVA-mediated phosphorylation of mTOR (a serine-threonine kinase involved in cell growth), an increase in $\mathrm{Ki}-67$ (a protein associated with cellular proliferation and ribosomal RNA transcription) and proliferating cell nuclear antigen (PCNA), an essential factor in DNA replication. Pre-treatment with the extract also increased UVA-induced cell-cycle arrest in the $\mathrm{G} 1$ phase and the expression of pro-apoptotic proteins Bax and Bad, with downregulation of the expression of the anti-apoptotic protein Bcl-xL (ref. ${ }^{33}$ ).

\section{Polypodium leucotomos}

The tropical fern Polypodium leucotomos (syn. Phlebodium aureum L. or Polypodium aureum L.) from the Polypodiaceae family is native to Central and South America. P. leucotomos is rich in phenolic compounds, especially benzoate and cinnamate derivatives. Chlorogenic, p-coumaric, vanillic, cinnamic, caffeic and ferulic acid are the most abundant of them, and these compounds are known for their photoprotective potential (see part Phytochemicals with UVA protective potential). P. leucotomos has been traditionally used for treating various skin disorders (e.g., psoriasis and atopic dermatitis) in its areas of origin ${ }^{34}$. Clinical scientific evidence suggests that $P$. leucotomos is also beneficial for the treatment of vitiligo and the prevention of polymorphic light eruption. Photoprotective activity has been assessed in animals, healthy volunteers as well as in patients suffering from several cutaneous diseases such as vitiligo, psoriasis, idiopathic photodermatosis or melasma ${ }^{35,36}$.

A hydrophilic extract of $P$. leucotomos efficiently protected NHDF and HaCaT survival and restored their proliferative capability when the cells were exposed to UVA radiation. The extract also prevented UVA-induced morphological changes in NHDF, especially the disorganisation of F-actin-based cytoskeletal structures, coalescence of the tubulin cytoskeleton and mislocalization of adhesion molecules such as cadherins and integrins ${ }^{37}$. P. leucotomos extract inhibited the protein expression of MMP-1 and MMP-2 and stimulated the levels of the tissue inhibitors of MMP-1 and -2 (TIMP-1 and TIMP-2) in UVA-irradiated NHDF and CRL-1619 melanoma cells. The extract pre-treatment also stimulated the protein levels of collagen I and V in UVA-radiated fibroblasts ${ }^{38}$. 
Oral pre-treatment of male hairless rats with $P$. leucotomos extract significantly reduced GSH oxidation and the formation of oxidized GSH (GSSG) in both erythrocytes and plasma stimulated with UVB/UVA radiation (9:10). The extract also significantly increased CAT activity and the GSHGSSG ratio, and reduced the depletion of Langerhans cells in the epidermis of irradiated animals ${ }^{39}$. The oral administration of $P$. leucotomos extract to human volunteers (phototypes II to III) reduced negative clinical signs of PUVA therapy, in particular phototoxic reaction and pigmentation. In the skin of individuals treated with the extract, a significant reduction in sunburn cells, preservation of Langerhans cells, decrease in mast cells infiltration, and decrease in vasodilation were found ${ }^{40}$.

\section{Vaccinium myrtillus}

Bilberry (Vaccinium myrtillus L.), is a well-known small shrub, also called blueberry, huckleberry or whortleberry that grows wildly in Northern Europe, North America, and Asia. Bilberry belongs to the Ericaceae family. The fruit is a blue-coloured, fleshy berry, which contains several bioactive secondary metabolites, including flavonoids, vitamins, sugars, and pectin. In terms of flavonoids, anthocyanins are the most widely studied class of bioactive compounds of this plant. Multiple pharmacological activities (related to the anthocyanidin fraction) include antioxidant, anti-inflammatory, anti-atherosclerosis, or wound healing ${ }^{41}$. Some studies showed the beneficial effects of bilberry on skin. For example anthocyanins from bilberry have been found to alleviate pruritus in a mouse model of chronic allergic contact dermatitis ${ }^{42}$ or to protect HaCaT against UVB-induced damage ${ }^{43}$.

The pre-treatment of HaCaT with $V$. myrtillus fruit extract resulted in the attenuation of UVA-stimulated ROS formation, lipid peroxidation and the depletion of intracellular GSH (ref. ${ }^{44}$ ). In another study, V. myrtillus extract increased the cell viability of $\mathrm{HaCaT}$ and reduced UVA-provoked ROS generation, malondialdehyde (MDA) production, DNA damage and the number of apoptotic cells ${ }^{45}$. Anthocyanins that are rich in the ethanolic extract from bilberry (BE) as well as BE-loaded ultra-deformable liposomes increased the viability of UVA-irradiated $\mathrm{HaCaT}$ (ref. $^{46}$ ).

\section{Lonicera caerulea}

Lonicera caerulea L., also called blue honeysuckle, honeyberry, edible honeysuckle or sweet berry honeysuckle, is a shrub from the Caprifoliaceae family. L. caerulea can be found mainly in northern Russia, China, and Japan. Its berries are oval to long in shape and dark navy blue to purple in colour. The fruits contain several groups of phenolics including anthocyanins, flavonoids and low-molecular-weight phenolic acids. These compounds have been reported to have multiple biological activities, including antioxidant, anti-inflammatory and cytoprotective $^{47}$. The potential of $L$. caerulea polyphenols and berries to reduce UVB-induced damage was demonstrated in vitro ${ }^{43}$ and in vivo ${ }^{48}$.
The pre- and post-treatment of $\mathrm{HaCaT}$ with the polyphenolic fraction of $L$. caerulea significantly increased cell viability and suppressed UVA-induced ROS production, lipid peroxidation and the depletion of reduced GSH (ref. ${ }^{49}$ ). Consuming L. caerulea berries reduced MDA production and increased CAT activity and GSH level in the skin and erythrocytes of hairless mice. The protein levels of NQO-1 and $\gamma$-GCL were reduced, while HO-1 level was increased in the skin of UVA-exposed mice fed L. caerulea berries. The plasma level of IL-17 was increased and of IL-12 was reduced in the mice consuming the berries exposed to UVA light. Histological changes in the nuclei of basal cells induced by UVA exposure were reduced in the animals consuming $L$. caerulea berries ${ }^{50}$.

\section{Thymus vulgaris}

A flowering, aromatic perennial herb from the Lamiaceae family, Thymus vulgaris L. is commonly known as thyme. T. vulgaris is native to southern Europe from the western Mediterranean to southern Italy. Abundant constituents of T. vulgaris include the terpenes thymol (2-isopropyl-5-methylphenol), carvacrol and borneol. Essential oils extracted from fresh leaves and flowers are used as aroma additives in food, pharmaceuticals and cosmetics. Thyme possesses various beneficial effects such as antioxidant, antiseptic, antimicrobial, carminative, antitussive, or spasmolytic $^{51}$. T. vulgaris extracts were reported to be immunomodulatory, anti-inflammatory or hepatoprotective agents $^{52}$. An ethanolic extract of T. vulgaris seeds reduced UVB-caused damage to NHDF and hairless mice $\operatorname{skin}^{53}$. T. vulgaris leaf water extract was demonstrated to reduce UVB-induced damage in ex vivo human skin $^{54}$.

A leaf extract from $T$. vulgaris and thymol protected the low differentiated keratinocyte cell line NCTC 2544 against UVA-induced damage, and especially reduced ROS level, lipid peroxidation and DNA damage ${ }^{55}$.

\section{Opuntia ficus-indica}

Opuntia ficus-indica L. Mill., commonly called prickly pear or nopal cactus, belongs to the dicotyledonous angiosperm Cactaceae family. O. ficus-indica is a tropical and subtropical plant that grows in arid and semiarid areas in Mexico, Latin America, South Africa and Mediterranean countries. The cactus cladodes contain vitamins and various phenolic acids and flavonoids, especially quercetin 3-methyl ether, a highly efficient radical scavenger. Extracts of $\boldsymbol{O}$. ficus-indica have antioxidant and anti-inflammatory activity and remarkably improve wound healing ${ }^{56}$.

Water extract from $O$. ficus-indica cladodes was shown to protect $\mathrm{HaCaT}$ against UVA radiation, particularly against UVA-induced ROS production, lipid peroxidation and GSH depletion. Moreover, the cleavage of caspase- 3 and caspase- 7 and the phosphorylation of $\mathrm{p} 38$ and MAPK-activated protein kinase 2 (proteins directly involved in stress signalling pathways induced by UVA radiation) were reduced in irradiated cells pre-treated with the extract ${ }^{57}$. 


\section{Morinda citrifolia}

Morinda citrifolia $\mathrm{L}$. is a tropical tree with a distinctive, ovoid, "grenade-like" yellow fruit. M. citrifolia, commonly known as noni (other names include Pain bush, Pain killer tree, Cheese fruit, Forbidden fruit, Headache tree, Nino, Pinuela, Hog apple or Wild pine), belongs to the Rubiaceae family. M. citrifolia is widely distributed in areas of Micronesia, Hawaii, Tahiti, Australia, and Southeast Asia. Various compounds were identified in its leaves, fruits and roots, such as vitamin $\mathrm{C}$ and $\mathrm{A}$, carotene terpenoids, alkaloids, anthraquinones, flavonoids and their glycosides. The fruits, roots, bark and leaves of M. citrifolia have been used throughout Polynesia as a folk medicine for the treatment of many diseases including various cancers, burns, skin inflammation and wounds ${ }^{58}$. M. citrifolia leaf extract was also shown to reduce UVBinduced erythema in human volunteers ${ }^{59}$.

An ethanolic extract of $M$. citrifolia seeds exhibited an inhibitory effect on MMP-1 secretion in UVA-irradiated NHDF. A constituent of the extract, 3,3-bisdemethylpinoresinol, inhibited this MMP-1 secretion as well. The compound also reduced the phosphorylation of $\mathrm{p} 38$ and JNK $\left(\right.$ ref. $\left.^{60}\right)$.

\section{Aloe vera}

Aloe vera $(\mathrm{L})$. Burm. f. (syn. Aloe barbadensis Mill.) is a perennial plant with thick, succulent, and long leaves that belongs to the Liliaceae family. A. vera grows easily in hot and arid regions. The $A$. vera plant contains phenolic compounds, anthracene hydroxyl derivatives (namely aloin A and B (collectively known as barbaloin) emodin, anthranol), enzymes (e.g., amylase, lipase, COX, SOD and CAT) and also pro-vitamin $\beta$-carotene, vitamins (B1, B2, B6, C, $\alpha$-tocopherol, and folic acid). The bioactive components in A. vera have been reported to have antifungal, antiseptic, antiviral, antibacterial, anti-inflammatory, antioxidant, immuno-modulatory and wound healing properties $^{61,62}$. Several studies also demonstrated beneficial effects of $A$. vera on UVB-induced damage ${ }^{63-65}$.

A whole-leaf extract of $A$. vera reduced UVA-induced photodamage to HaCaT. The extract increased cell viability, membrane integrity and lysosomal stability and reduced ROS generation and morphological changes (cell size, granularity) (ref. $\left.{ }^{66}\right)$.

\section{Oenothera paradoxa}

Evening primrose (Oenothera paradoxa Hudziok) is a biennial herb originating from Mexico and Central America, belonging to the Oenotheraceae family. Today, it is also cultivated in Europe and parts of Asia for the production of seeds that are a great source of $\gamma$-linolenic acid. Defatted seeds represent a prominent source of polyphenolic compounds (flavonoids, phenolic acids, and hydrolyzable tannins). In traditional medicine, the whole plant or leaf juice is used for its analgesic and wound healing properties, especially as topical remedies to alleviate cutaneous inflammation. A number of studies demonstrated the antioxidant activity of $O$. paradoxa defatted seed extract $^{67,68}$. O. paradoxa defatted seed extract exhibited an antimigratory, anti-invasive and antimetastatic potential towards prostate and breast cancer cells ${ }^{69}$. An anticancer activity of $O$. paradoxa defatted seeds extract was also found on skin melanoma cells ${ }^{70}$.

The pre-treatment of NHDF with an aqueous extract of $O$. paradoxa defatted seeds increased the number of viable cells, decreased the release of lactate dehydrogenase (LDH), ROS production, lipid peroxidation and the number of cells in late apoptosis after UVA exposure ${ }^{71}$.

\section{Galinsoga parviflora and Galinsoga quadriradiata}

Galinsoga parviflora Cav. and G. quadriradiata Ruiz et Pavón are annual herbs belonging to the Asteraceae family originating from the Andes region. The chemical composition of Galinsoga herbs is similar. They contain flavonoids and their glycosides (patulitrin (patuletin-7-O- $\beta$-D-glucoside), quercimeritrin (quercetin7-O- $\beta$-D-glucoside), quercetagetrin (quercetagetin-7-O- $\beta$ D-glucoside), luteolin 7- $\beta$-D-glucopyranoside, apigenin 7- $\beta$-D-glucoside, galinsoside A (5'-hydroxy-7-methoxyflavanone 2'-O- $\beta$-D-glucopyranoside), galinsoside B (3',4'-dihydroxy-7-methoxyflavanone 5-O- $\beta$-D-glucopyranoside), 7,3',4'-trihydroxyflavanone and 3,5,7,3',4'-pentahydroxyflavanone, and phenolic acids and depsides (vanillic, isovanillic, $p$-coumaric, $p$-hydroxybenzoic, $o$-hydroxyphenylacetic, caffeic, chlorogenic acid and caffeoylglucaric acids and other compounds. The topical application of Galinsoga species extracts is used to treat dermatological diseases, such as eczemas, lichens and poorly healing wounds, and also to treat snakebites ${ }^{72}$.

The aqueous extracts of both herbs decrease ROS production and apoptosis in UVA- or UVB-treated NHDF $\left(\right.$ ref. $\left.^{72}\right)$. Two isolated caffeic derivatives from G. parviflora, 2,3,5(2,4,5)-tricaffeoylaltraric and 2,4(3,5)-dicaffeoylglucaric acid, decreased LDH release, intracellular ROS formation and the number of apoptotic cells, and increased GSH level and membrane integrity in UVA-exposed NHDF. Both compounds activated transcription factor Nrf2 and HO-1 expression in non- and/or UVA-exposed $\operatorname{NHDF}\left(\right.$ ref. $\left.^{73}\right)$.

\section{Hippophae rhamnoides}

Sea buckthorn (Hippophae rhamnoides L.) is a spiny deciduous flowering shrub in the Elaeagnaceae family. It is native to the cold-temperate regions of Europe and Asia. It is used in the food and cosmetics industries. The oil prepared from soft parts and from the seeds is rich in vitamins ( $\mathrm{C}, \mathrm{E}$ and $\mathrm{K})$, polyphenols, carotenoids, sterols, minerals, amino acids, saturated and unsaturated fatty acids. The H. rhamnoides seed oil protected a UVA- and UVB-treated CDD 1102 KERTr human keratinocyte cell line and CCD 1112Sk human fibroblasts. The oil pretreatment prevents the UVA-stimulated production of ROS and depletion of non-enzymatic antioxidants (thioredoxin (Trx), GSH and vitamins A and E) and enzymatic antioxidants (SOD, glutathione reductase (GSR), GPx, Trx reductase (TrxR)) and stimulated the Nrf2 dependent enzymatic antioxidant HO-1. Sea buckthorn oil also inhibited UVA- or UVB-stimulated phospholipase A2 
activity and the production of lipid peroxidation products, 4-hydroxynonenal (4-HNE) and 8-isoprostaglandin F2 $\alpha$. The modulation of endocannabinoid receptors $\mathrm{CB} 1$ and CB2 was specific for the different types of UV radiation and skin cells ${ }^{74}$.

\section{Cola acuminata}

Cola nut (Cola acuminata Schott \& Endl. or Sterculia acuminata) also called "kola nut" is a popular edible plant native to West Africa. The seed of this large tree has been used in African folk medicine namely for aiding digestion and coughs. The main constituents of cola nut are caffeine, theobromine, and polyphenols, including D-catechin, L-epicatechin, procyanidin B1 and B2 and tannins ${ }^{75-77}$. The benefitial health effects of substances mentioned above are so notable as chocolade is explored as functional food ${ }^{76}$. Topically applied cola nut extract, and pure alkaloids theobromine, theophylline and caffeine markedly reduced UVA-induced wrinkle formation and histological alterations in dorsal skin of hairless mice, including changes in extracellular matrix proteins and infiltration of leukocytes ${ }^{77}$.

\section{Theobroma cacao}

Theobroma cacao L., also called cocoa tree and cacao tree is an evergreen tree in the family Malvaceae, native to tropical regions Central and South America. Cacao beans have been traditionally used to treat the pain of pregnancy, fever, and cough in Central America. Cacao beans contain flavonoids, catechins, epicatechins, procyanidins and xanthine derivatives (caffeine and theobromine). Cacao has been reported to have anti-inflammatory effect, modulates $\mathrm{NF}-\mathrm{kB}$ and redox sensitive signalling pathways, stimulates immune response, influence insulin resistance and has positive effect on cardiovascular system ${ }^{78,79}$. Topical application of cacao beans extract suppressed wrinkle formation, changes in dermal connective tissue and neutrophil infiltration caused by UVA-irradiation in vivo ${ }^{77}$.

\section{Amaranthus cruentus}

Amaranthus cruentus L. is an annual plant with dark pink flowers. Its grains known as amaranth seeds are used as cereal, rich to flavonoids, phenolic acids, essential amino acids, bioactive peptides, micro- and macronutrients including minerals and vitamins. Amaranth seeds contain hydrophilic and hydrophobic antioxidants that contribute anti-inflammatory activity, in lowering risk of the oxidative stress related diseases (diabetes, obesity, cardiovascular disease) and improving gut health. Oil obtained by cold-pressing the grain is valuable due to the presence of unsaturated fatty acids, tocopherols, tocotrienols, phytosterols, and squalene $\mathrm{e}^{80,81}$. A recent study evaluated effect of pre- and post-treatment with amaranth oil on UVAirradiated human skin fibroblasts. The amaranth oil activity was rather poor and its use in combination with other sunscreens is recommended ${ }^{82}$.

\section{PHYTOCHEMICALS WITH UVA PROTECTIVE POTENTIAL}

\section{Ferulic acid}

Ferulic acid (FA, 4-hydroxy-3-methoxycinnamic acid) is a ubiquitous phenolic acid found in Commelinidae plants (rice, wheat, oats, and pineapple), grasses, grains, vegetables, flowers, fruits, leaves, beans, coffee beans, artichoke, peanut and nuts, in its free or conjugated (e.g., polysaccharides, glycoproteins, polyamines) form. FA is more easily absorbed into the body and stays in the blood longer than any other phenolic acids. FA exhibits a wide range of biological effects including antioxidant, anti-inflammatory, anti-allergic, anticarcinogenic, antimicrobial, antiviral, hepatoprotective, vasodilatory or antithrombotic ${ }^{83}$. Its structure (Fig. 2) is similar to tyrosine and thus FA inhibits melanin formation through competitive inhibition with tyrosine ${ }^{84}$. FA is a strong UV absorber. FA alone ${ }^{85}$ or in combination with vitamin $\mathrm{C}$ and $\mathrm{E}$ (ref ${ }^{86,87}$ ) exhibited a considerable protection against UVB-induced skin damage, including UVB-induced carcinogenesis.

Relative to UVA light, the FA pre-treatment of the B16F10 mouse melanoma cell line led to the inhibition of UVA-induced melanin synthesis as well as tyrosinase activity and its protein expression. FA also reduced UVA-induced ROS and 8-OH-dG formation and GSH depletion $^{88}$. In $\mathrm{HaCaT}$, FA pre-treatment reduced the UVA-induced decrease in cell viability, ROS formation and the induction of MMP-1 activity and mRNA expression. Moreover, FA was able to upregulate GSH content, $\gamma$-GCL mRNA level as well as the activities and mRNA expression of CAT and GPx in UVA-irradiated cells ${ }^{89}$. The pre-treatment of NHDF with FA increased cell viability after exposure to various UVA doses. UVA-stimulated G1phase arrest in NHDF was also reduced by FA in a dosedependent manner. Cells pre-treated with FA exhibited its effect on nucleotide excision repair with a significant increase in the expression of the genes of xeroderma pigmentosum complementation group $\mathrm{A}$ and $\mathrm{C}$. FA reduced UVA-induced ROS formation and increased the levels of SOD-1 and CAT mRNA. FA also inhibits cellular senescence by reducing senescence-related markers, especially $\beta$-galactosidase activity and the mRNA expression of tumour suppressor protein p16, MMP-1 and MMP-3 (ref. ${ }^{90}$ ). The in vivo application of FA in the form of a nanogel significantly increased the level of SOD, GPX and CAT and reduced the MDA level in UVA-irradiated rat skin ${ }^{91}$.

\section{Caffeic acid}

Another abundant phenolic acid, caffeic acid (CA, 3,4-dihydroxycinnamic acid, Fig. 2) occurs in free and/or various combined forms in a large number of fruits (e.g., blueberries, gooseberries, blackcurrant, orange, lemon, pears), vegetables (e.g., kale, radishes, cabbage, Brussels sprouts, carrots, celery, lettuce, potatoes, eggplant), and herbs (e.g., thyme, sage, basil, oregano) as well as in bee propolis, olive oil and beverages (e.g., apple juice, wine, tea and coffee) (ref. $\left.{ }^{92,93}\right)$. Studies have demonstrated antioxidant, anti-inflammatory, antitumour and antimeta- 


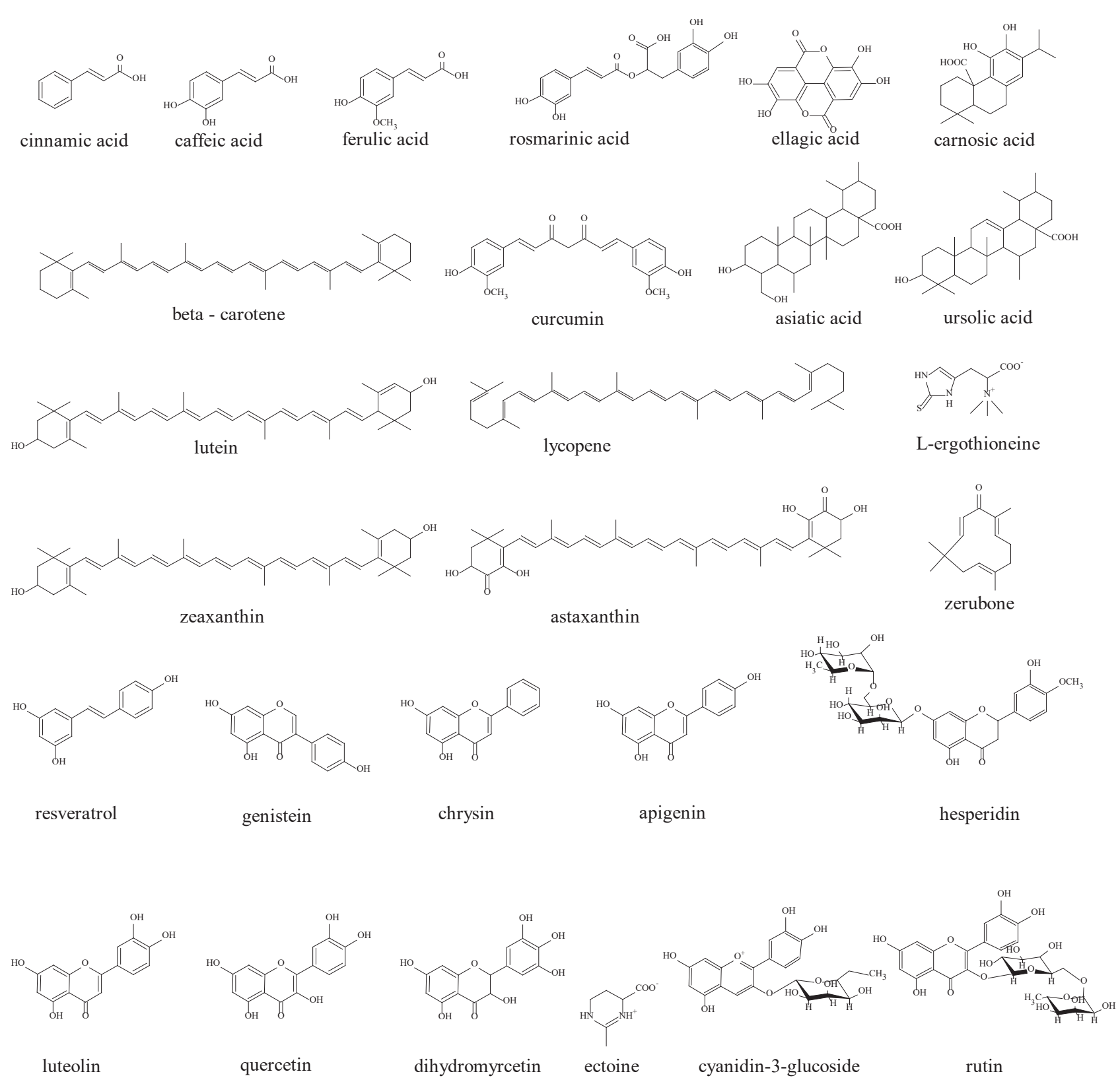

Fig. 2. Structures of phytochemicals with UVA protective potential.

static effects of CA (ref. $\left.{ }^{93}\right)$. Several papers documented a UVB protective potential of CA (ref. ${ }^{93}$ ).

In a B16F10 mouse melanoma cell line, CA pretreatment reduced UVA-induced melanin synthesis and tyrosinase activity and the protein's expression. CA also reduced UVA-induced ROS and $8-\mathrm{OH}-\mathrm{dG}$ production and GSH depletion. CA further inhibited the UVA-mediated downregulation of the nuclear level of Nrf-2, the mRNA level of the $\gamma$-GCL catalytic and modifier subunit, GST and NQO1, and the protein level and activity of $\gamma$-GCL, GST and NQO1 (ref. ${ }^{88}$ ). In HaCaT, CA reduced UVAinduced cytotoxicity, ROS formation and the induction of MMP-1 activity and mRNA expression. Moreover, CA upregulated GSH content, $\gamma$-GCL mRNA level as well as the activities and mRNA level of CAT and GPx in UVAexposed cells ${ }^{89}$. The topical and oral treatment of hairless mice suppressed intrinsic and UVA-induced ROS generation in skin tissue ${ }^{97}$.

\section{Cinnamic acid}

Cinnamic acid (CIN, 3-phenylacrylic acid) is a phenolic acid generally obtained from cinnamon (Cinnamomum cassia (L.) J. Pres1). Other sources include citrus fruits, grapes (Vitis vinifera L.), tea (Camellia sinensis (L.) Kuntze), cocoa (Theobroma cacao L.), spinach, celery and brassica vegetables ${ }^{98}$. CIN processes several pharmacological activities, including antioxidant, antimicrobial, anticancer and anti-inflammatory. CIN exists in trans- or cis-form. The trans-CIN ( $t$-CIN, Fig. 2 ) is the predominant form in nature due to its high stability ${ }^{99}$. CIN was demonstrated to be a potent inhibitor of tyrosinase activity, it also inhibited tyrosinase expression and 
melanin production in vitro, and exhibited a depigmenting activity on a UVB-induced hyper-pigmentation model in vivo ${ }^{100}$.

The pre-treatment of Hs68 human foreskin fibroblast-derived cells with $t$-CIN reduced UVA-induced cytotoxicity, ROS generation, MMP-1 and MMP-3 overexpression and procollagen type I degradation. $t$-CIN also inhibited UVA-induced photoaging via the suppression of activator protein 1 activation. $t$-CIN enhanced the nuclear translocation of Nrf2 as well as inducing HO-1 and $\gamma$-GCL protein expression. $t$-CIN-induced Nrf2 translocation was mediated through protein kinase C (PKC), AMP-activated protein kinase, casein kinase II or ROS signalling cascades. Topically applied $t$-CIN significantly suppressed MMP-1 and MMP-3 activation and maintained sufficient type I procollagen levels in the skin of repeatedly UVAirradiated female athymic nude mice (BALB/c-nu) $\left(\right.$ ref. $\left.{ }^{99}\right)$.

\section{Rosmarinic acid}

Rosmarinic acid (RA), a phenolic acid, is an ester of caffeic acid and 3,4-dihydroxyphenyllactic acid (Fig. 2). It got its name according to its initial isolation from rosemary (Rosmarinus officinalis). RA is commonly found in species of the Lamiaceae family. However, it is also found in species of other higher plant families and in some fern and hornwort species. RA occurs in species used commonly as culinary and/or medicinal plants such as Ocimum basilicum (basil), Melissa officinalis (lemon balm), Origanum majorana (marjoram), Salvia officinalis (sage), Thymus vulgaris (thyme), Mentha piperita (peppermint) or Prunella vulgaris (self-heal) (ref. ${ }^{101,102}$ ). RA has a number of interesting biological activities, e.g., antioxidant, anti-inflammatory, antiviral or antibacterial ${ }^{101}$. Several studies found RA to possess the ability to reduce UVB-induced damage to HaCaT (ref. ${ }^{103-105}$ ).

Topically applied RA exhibited a concentration-dependent suppressive effect on intrinsic and UVA-induced ROS generation in the skin of hairless mice ${ }^{97}$. The oral administration of RA to female albino Swiss mice led to a reduction in cutaneous dysplasia provoked by chronic UVA exposure ${ }^{106}$. The post-treatment of UVA-irradiated $\mathrm{HaCaT}$ with RA increased cell viability and reduced ROS production, intracellular lipid peroxidation, ATP and GSH depletion as well as DNA damage and the activation of caspase-3 (ref. ${ }^{107}$ ).

\section{Curcumin}

Curcumin (CUR, diferuloylmethane, Fig. 2) is a yellow-coloured compound extracted from the rhizome of Curcuma longa L. (turmeric). CUR has been employed as a culinary spice and for the treatment of various diseases, including skin disorders and wound healing, dating back to 4000 years $\mathrm{ago}^{108}$. CUR decreased UVB-induced oxidative stress, inflammation and DNA damage in vitro ${ }^{109}$ and in vivo ${ }^{110}$.

In UVA-exposed NHDF, CUR reduced the formation of ROS, endoplasmic reticulum stress, inflammation and apoptosis, and increased the activity of antioxidant defence enzymes (SOD and CAT). CUR also influenced collagen metabolism by decreasing MMP-1 and MMP-3 expression and promoted the reparation of cells by increasing the expression of transforming growth factor- $\beta$ (TGF- $\beta$ ) and the protein Smad2/3, and decreased the expression of Smad7, a TGF- $\beta$ inhibitor ${ }^{111}$.

\section{Quercetin}

The flavonol quercetin (QE, 3,3',4',5,7-pentahydroxyflavone; 2-(3,4-dihydroxyphenyl)-3,5,7-trihydroxy-4H1-benzopyran-4-one, Fig. 2) is one of the most abundant naturally occurring polyphenols. It is present, primarily in the form of glycosides, in many fruits (e.g., apples, cranberries, cherries, grapes, lemon), vegetables (e.g., onion, peppers, asparagus, lettuce, tomato, broccoli, kale), herbs (e.g., Gingko biloba, Apocynum venetum, Poacynum hendersonii, Opuntia ficus-indica), olive oil, bee propolis or beverages such as wine and black or green tea ${ }^{112,113}$. Numerous biological effects of QE have been published in a great number of in vitro and in vivo studies. Specifically, QE exhibits antioxidant, anti-inflammatory, immunoprotective, and anticarcinogenic effects ${ }^{112}$. QE also possesses UVB protective activity ${ }^{114-116}$.

QE pre-treatment was found to reduce UVA-induced ROS and 8-OH-dG production, GSH depletion, melanin synthesis as well as tyrosinase activity and the protein's expression in B16F10 melanoma cells. QE also inhibited the UVA-mediated downregulation of nuclear Nrf2 level and Nrf2-antioxidant responsible element (ARE) transcriptional activity in cells. QE prevented the UVA-mediated mRNA downregulation of GST, NQO1 and $\gamma$-GCL catalytic and modifier subunit as well as the decrease in protein expression and activity of the Nrf2 target antioxidant enzymes (particularly GST, NQO1 and $\gamma$-GCL) (ref. ${ }^{88}$ ). Further, QE pre-treatment suppressed UVA-induced ROS production, GSH depletion and apoptosis in $\mathrm{HaCaT}$ (ref. ${ }^{117}$ ). QE pre-treatment significantly decreased UVA-induced DNA damage to C3H10T1/2 mouse embryo fibroblasts) (ref. ${ }^{118}$ ) and inhibited UVAstimulated collagenase protein and mRNA level in NHDF $\left(\right.$ ref. $^{119}$ ). In the EpiDerm ${ }^{\mathrm{TM}}$ model, QE significantly decreased UVA-induced MMP-1 and tumour necrosis factor alpha $(\mathrm{TNF}-\alpha)$ secretion ${ }^{120}$. The intraperitoneal application of QE before repeated UVA exposure resulted in a reduced MDA level and increased activities of GPx, GSR, CAT and SOD in the skin ${ }^{121}$, erythrocytes ${ }^{122}$ and liver tissue ${ }^{123}$ of female Spraque-Dawley rats. QE was also found to enhance the photostability (UVA+UVB) of the two UV filters, butyl methoxydibenzoylmethane and octyl methoxycinnamate in oil-in-water emulsions ${ }^{124}$.

On the other hand, QE was shown to undergo slow decomposition to a mixture of C-ring-opened products. The presence of a triplet sensitizer greatly increases UV radiation-mediated QE decomposition. Thus the presence of endogenous photosensitizers in the skin could potentially affect the UV stability of QE, suggesting that the further study of QE for both its photoprotective properties and photostability in skin is warranted ${ }^{125}$. Besides a dosedependent photodegradation in aqueous and organic environments, QE exhibited a phototoxic effect on fibroblasts (Balb/c 3T3 cells and NHDF) and keratinocytes (HaCaT and NHEK). QE pre-treatment and subsequent UVA ex- 
posure further resulted in increased ROS production and intracellular GSH level depletion in NHDF (ref. ${ }^{126}$ ).

\section{Apigenin}

Apigenin (AP, 4',5,7,-trihydroxyflavone; 5,7-dihydroxy2-(4-hydroxyphenyl)-4H-1-benzopyran-4-one, Fig. 2) is a abundantly distributed plant flavone occurring in herbs (e.g., endive, clove, chamomile), fruits (e.g., apples, grapefruit, oranges, cherries, grapes), vegetables (e.g., beans, broccoli, celery, leeks, onions, barley, parsley, tomatoes) and beverages (e.g., tea, wine). In nature AP also exists as a dimer, biapigenin, mainly isolated from the buds and flowers of Hypericum perforatum ${ }^{127}$. In numerous mammalian systems in vitro as well as in vivo, AP demonstrated antioxidant, anti-inflammatory, antiviral and anticancer properties $^{127}$. AP increased dermal density and elasticity and reduced fine wrinkle length as well as improving skin evenness, moisture content and transepidermal water loss (TEWL) in human volunteers ${ }^{128}$. Several studies also documented its UVB photoprotective potential ${ }^{129}$.

The AP pre-treatment of NHDF reduced MMP-1 protein and mRNA level in UVA-exposed cells ${ }^{119}$. AP further increased cell viability and inhibited ROS production in UVA-irradiated HaCaT. AP also decreased UVAstimulated mRNA expression and activity of MMP-1 as well as the protein and mRNA expression of transcription factors c-Jun and c-Fos and the phosphorylation of MAPK, particularly ERK1/2, JNK1/2 and p38 MAPK. AP further decreased the UVA-induced influx of $\mathrm{Ca}^{2+}$ into $\mathrm{HaCaT}$ and the phosphorylation of $\mathrm{Ca}^{2+} /$ calmodulin-dependent kinases ${ }^{130}$. Pre-treatment with AP also protected NHDF against UVA-induced senescence. The AP posttreatment of UVA-exposed NHDF increased cell viability and decreased the expression of MMP-1 (ref. ${ }^{128}$ ). A photosafety study found AP photostability in the UVA and VIS range and no phototoxic potential in the $3 \mathrm{~T} 3$ neutral red uptake phototoxicity test after UVA/VIS exposure ${ }^{131}$.

\section{Luteolin}

Luteolin (LU, 3', 4', 5, 7-tetrahydroxyflavone; 2-(3,4-dihydroxyphenyl)-5,7-dihydroxy-4-chromenone, Fig. 2) is a flavone abundantly present in several plants including spices, vegetables, fruits and medicinal herbs, e.g., broccoli, pepper, thyme, peppermint, rosemary, oregano, parsley, celery, carrot, cabbage, artichoke, tea, celery, citrus fruits (especially oranges) and apples. Literary sources show that LU possesses antioxidant, anticancer, antiinflammatory or neuroprotective effects ${ }^{132}$.

LU exhibited an inhibitory effect on the MMP-1 protein and mRNA level in NHDF (ref. ${ }^{119}$ ). Pre-treatment of $\mathrm{HaCaT}$ with LU increased cell viability and reduced ROS generation after UVA exposure. LU also inhibited UVAinduced mRNA expression and the activity of MMP-1 as well as the protein and mRNA expression of transcription factors c-Jun and c-Fos and the phosphorylation of kinases (ERK1/2, JNK1/2 and p38 MAPK). LU further decreased the UVA-induced influx of $\mathrm{Ca}^{2+}$ into $\mathrm{HaCaT}$ and the phosphorylation of $\mathrm{Ca}^{2+} /$ calmodulin-dependent kinases $^{130}$. The application of LU to UVA-exposed NHDF decreased ROS production and non-apoptotic programmed cell death (autophagy). In addition, the protein expression of hypoxia inducible factor- $1 \alpha$ and the classical autophagy-associated proteins, microtubule-associated protein light chain 3 and beclin 1 were decreased in the UVA-irradiated NHDF (ref. ${ }^{133}$ ).

\section{Rutin}

Rutin (RU, 3,3',4',5,7-pentahydroxyflavone-3-rhamnoglucoside) also known as rutoside, quercetin 3-rutinoside, and sophorin, is a flavonol glycoside composed of quercetin and the disaccharide rutinose (Fig. 2). RU is abundantly found in plants, such as passion flower, buckwheat, tea, apples, lemons, and onions. RU exhibits several pharmacological properties including antioxidant, anticarcinogenic, cytoprotective, antiplatelet, antithrombotic, vasoprotective, cardioprotective and neuroprotective $^{134}$. As for the skin, RU was shown to increase skin elasticity and decrease signs of skin aging, especially the length, area and number of wrinkles in human volunteers. RU also increased the mRNA expression of collagen I and decreased the mRNA expression of collagenase in NHDF (ref. ${ }^{135}$ ). The UVB protection of RU is also quite well documented in vitro and in vivo ${ }^{134,136-139}$.

The RU pre-treatment of NHDF strongly protected against the UVA-induced increase in expression of proteins involved in antioxidant (such as SOD, TrxR, and peroxiredoxins 1/2) and inflammatory (e.g., IL-17, serine/ threonine-protein kinase 2, and tyrosine 3-monooxygenase/tryptophan 5-monooxygenase activation protein zeta) response $^{136}$. RU also reduced the UVA-induced oxidative modification of the membrane of CCD 1112Sk human fibroblasts, specifically the negative charge on the membrane surface, sialic acid concentration and level of lipid peroxidation $^{137}$. In another study on CCD 1112Sk human fibroblasts, RU application also counteracted ROS generation and prevented UVA- and UVB-induced changes in the composition of membrane phospholipids and free fatty acids content, the oxidation of phospholipids and biomembrane destruction, depletion of the GSH/GSSG ratio, GPx activity and levels of vitamins $\mathrm{E}$ and $\mathrm{C}$ (ref. ${ }^{140}$ ). RU further reduced UVA-induced pro-inflammatory response and ROS generation, and enhanced the activity/ level of antioxidants (SOD, GPx, vitamin E, GSH, and Trx). RU also normalized UVA-induced Nrf2 expression and prevented changes in the levels of the lipid peroxidation markers MDA and 4-HNE. RU pre-treatment prevented the protein modifications (particularly tyrosine derivatives formation) and decreased the levels of the proapoptotic markers caspase- 3 and cytochrome c (ref. ${ }^{138}$ ). The pre-treatment of B16F10 cells with RU lead to the inhibition of UVA-induced melanin synthesis as well as the activity and protein expression of tyrosinase, a reduction in UVA-induced ROS and 8-OH-dG formation and GSH depletion ${ }^{88}$. The pre-treatment of C3H10T1/2 fibroblasts with RU significantly decreased UVA-induced DNA damage $^{118}$. RU also reduced UVA-stimulated damage to a CDD 1102 KERTr immortalized keratinocyte cell line and CCD 1112Sk human fibroblasts. RU especially stimu- 
lated antioxidant enzyme activity (CAT, SOD, TrxR) and reduced ROS generation. The effect of RU was increased by its combination with ascorbic acid, which besides other effects stimulated the UV-induced activity of the transmembrane transporter bilitranslocase, responsible for the transport of RU into cells ${ }^{139}$.

\section{Chrysin}

Chrysin (CH, 5,7-dihydroxyflavone; 5,7-dihydroxy2-phenyl-4H-chromen-4-one, Fig. 2), is a natural flavone occurring in honey, propolis, the mushroom Pleurotus ostreatus and many plants e.g., chamomile or blue passion flower (Passiflora caerulea), which is used for commercial $\mathrm{CH}$ preparation ${ }^{141}$. $\mathrm{CH}$ exhibits many biological activities such as antioxidant, anti-inflammatory, anti-aging, antibacterial, anti-angiogenic and anticarcinogenic ${ }^{142} . \mathrm{CH}$ demonstrated an inhibitory effect on the protein and mRNA expression of MMP-1 in NHDF (ref. ${ }^{119}$ ). CH pretreatment attenuated UVA-induced damage to $\mathrm{HaCaT}$, especially the reduction of cell viability, ROS production, caspase-3 activation and COX-2 protein level. $\mathrm{CH}$ also inhibited JNK phosphorylation and mildly attenuated p38 and ERK1/2 phosphorylation ${ }^{143}$. Although $\mathrm{CH}$ was photostable in the UVA and VIS range, it exhibited phototoxic potential in the 3T3 neutral red uptake phototoxicity test $^{131}$.

\section{Dihydromyricetin}

The flavanonol dihydromyricetin (DHM, 3,5,7-trihydroxy-2-(3,4,5-trihydroxyphenyl)-2,3-dihydrochromen4-one) is also known as ampelopsin (Fig. 2). It is found in the Ampelopsis species, and Chinese vine tea (Ampelopsis grossedentata) is used for DHM isolation. DHM possesses numerous pharmacological activities, including antioxidant, anticancer, antimicrobial and hepatoprotective ${ }^{144}$. The consumption of DHM was found to reduce UVBinduced photoaging in mice ${ }^{145}$.

The DHM pre-treatment of HaCaT attenuated UVAinduced ROS generation, mitochondrial membrane potential decrease, lipid peroxidation, GPx protein decrease and the phosphorylation of histone $\gamma-\mathrm{H} 2 \mathrm{AX}$, a sensitive biomarker for DNA damage. DHM also reduced the mRNA level of IL-1 $\beta$, IL-6, COX-2 and Bax, increased the expression of the anti-apoptotic proteins Bcl-2 and Bcl-xL, and decreased the expression of the pro-apoptotic protein Bax as well as the activation of caspase-3. Additionally, DHM treatment also prevented the nuclear translocation of NF$\kappa \mathrm{B} /$ p65 and phosphorylation of c-Jun (ref. ${ }^{146}$ ).

\section{Genistein}

The isoflavone genistein (GE, 5,7,4'-trihydroxyisoflavone; 5,7-dihydroxy-3-(4-hydroxyphenyl)chromen-4-one, Fig. 2) is abundantly found in soy and other legumes. GE also exists in the glycosylated form genistin. GE acts as a selective estrogen receptor modulator. Several in vitro and in vivo studies demonstrated the beneficial effects of $\mathrm{GE}$ on skin, e.g., for the treatment of keloid scars, stimulation of collagen biosynthesis, acceleration of wound healing or protection of UVB-induced photodamage ${ }^{147}$.
As for UVA light, GE suppressed 8-OH-dG formation in purified UVA-irradiated DNA (ref. ${ }^{148}$ ). The application of GE significantly decreased psoralen and UVA-induced (PUVA) photodamage in hairless mice, especially skin thickening, cutaneous erythema and ulceration, inflammatory changes throughout the epidermis and PCNApositive cells, and completely inhibited the cleavage of poly (ADP-ribose) polymerase and caspase-3 (ref. ${ }^{149}$ ).

\section{Hesperidin}

Hesperidin (HE, (3',5,7-trihydroxy-4'-methoxyflavanone-7-rutinoside) is a flavanone glycoside, comprised of the aglycone hesperetin and the disaccharide rutinose (Fig. 2). HE is isolated in large amounts from the rinds of the ordinary orange Citrus aurantium L., Citrus sinensis, Citrus unshiu and other species of the genus Citrus (family Rutaceae). It has been reported to occur in many plants other than Citrus, such as in the families Fabaceae, Betulaceae, Lamiaceae and Papilionaceae. $\mathrm{HE}$ has been reported to possess significant antioxidant, anti-inflammatory, analgesic, immunomodulatory and wound healing effects ${ }^{147}$. Several reports also demonstrated a UVB-protective potential of HE in vitro ${ }^{151,152}$ and in vivo ${ }^{153,154}$

HE significantly prevented UVA-induced oxidative damage, in particular increased cell viability and SOD activity and reduced MDA level in HaCaT. Also a decrease in TNF- $\alpha$, IL1- $\beta$ and IL-6 protein and mRNA was observed $^{155}$.

\section{Chrysanthemin}

Chrysanthemin is one of the most common anthocyanins, also known as kuromanin or cyanidin-3-O-glucoside and cyanidin-3-O- $\beta$-glucopyranoside (CG; Fig. 2) $\mathrm{CG}$ is found in a variety of fruits and vegetables, including strawberries, blackberries, blueberries, raspberries, cherries, pomegranate, pigmented oranges, red cabbage, black rice, black beans or purple sweet potatoes ${ }^{156}$. CG is a potent antioxidant and protects against oxidative damage ${ }^{157}$. CG was also reported to reduce UVB-induced damage in $v i$ tro ${ }^{158-160}$ and in vivo ${ }^{161,162}$.

The CG pretreatment of HaCaT cells inhibited the UVA-induced formation of apoptotic cells and DNA fragmentation as well as hydrogen peroxide production ${ }^{157}$. CG increased cell viability, Bcl-2 expression, Bcl-2/Bax ratio and ERK phosphorylation and decreased ROS production and the levels of caspase- 3 and phosphorylated p38 in UVA-irradiated NHDF (ref. ${ }^{163}$ ).

\section{Resveratrol}

Resveratrol (RE, trans-3,5,4'-trihydroxystilbene, Fig. 2) is a polyphenol belonging to the stilbenoid class. It is a phytoalexin synthesized mainly in grapes, with higher quantities in the red varieties. Other plant sources include peanuts, hops, cacao and berries (blueberries, bilberries, and cranberries) (ref. ${ }^{164}$ ). RE is an effective antioxidant and anti-inflammatory agent. In vitro studies demonstrated its antiproliferative activity in various skin cancer cells. 
Several in vitro and in vivo studies have also demonstrated the UVB photoprotective activity of RE (ref. ${ }^{164,165}$ ).

In retinal pigment epithelial (RPE) cells, RE reduced the UVA-provoked decrease in cell viability, the generation of intracellular hydrogen peroxide and COX-2 expression. RE also lowered the UVA-induced activation of ERK, JNK and p38 kinase in RPE cells ${ }^{166}$. The pre- and posttreatment of $\mathrm{HaCaT}$ cells with $\mathrm{RE}$ resulted in an increase in cell viability, and a reduction in lipid peroxidation and ROS production. Moreover, RE facilitated Nrf2 accumulation in the nucleus; as a result, the activities of the antioxidant enzymes GST and SOD were also enhanced. Kelch-like ECH-associated protein 1 (Keap1), a repressor of Nrf2 in the cytoplasm, was clearly reduced by RE treatment while the level of Keap 1 mRNA was still increased $^{167}$. A derivative of RE, oxyresveratrol (oxyRE), increased cell viability and suppressed intracellular ROS when cells were pre-treated before UVA exposure. Posttreatment with oxyRE reduced nitrotyrosine, 8-OH-dG and CPDs formation and stimulated p53 expression ${ }^{168}$.

On the other hand, the pre-treatment of $\mathrm{HaCaT}$ and NHEK with RE caused a massive increase in oxidative stress in mitochondria, leading to a decrease in the mitochondrial membrane potential and consequently to apoptosis of the keratinocytes ${ }^{169}$. Another study showed that RE potentiates the production of $8-\mathrm{OH}-\mathrm{dG}$ in UVAirradiated genomic DNA. Moreover, the combination of RE with UVA significantly enhanced the production of DNA strand breaks and the cell death of HaCaT (ref. ${ }^{170}$ ). In NHEK, RE enhanced the response stimulated by UVA+UVB (10:1), as it had a synergistic effect on the activation of the aryl hydrocarbon receptor pathway, cytochrome P450 1A1 transcription and IL-8 expression, as well as on NFkB activation and the nuclear translocation of the epidermal growth factor receptor ${ }^{171}$. These suggest that RE might have a potentially hazardous effect when topically applied to the skin, especially on regions exposed to sunlight.

\section{Ellagic acid}

Ellagic acid (EA, 2,3,7,8-tetrahydroxy-chromeno[5,4,3cde]-chromene-5,10-dione; 4,4',5, 5',6,6'-hexahydroxydiphenic acid 2,6,2',6'-dilactone, Fig. 2) is a polyphenol, present in several fruits, vegetables, nuts, and a wide variety of berries, including blackberries, raspberries, strawberries, cranberries and pomegranates. EA was demonstrated to eliminate ROS, activate specific endogenous antioxidant enzymes and suppresses specific genes responsible for inflammation. It also possesses antimutagenic and anticancer properties ${ }^{172}$. EA was shown to reduce UVB-induced damage in terms of inflammatory response ${ }^{104}$.

EA pre-treatment markedly increased HaCaT cell viability and suppressed UVA-induced ROS generation and lipid peroxidation. Moreover, EA pre-treatment reduced single-strand break formation and apoptosis by reducing DNA fragmentation, mitochondria dysfunction, endoplasmic reticulum stress, caspase- 3 activation, and Bcl2/Bax deregulation in irradiated cells. The antioxidant potential of EA was demonstrated as the downregulation of Keap 1 and the augmented nuclear translocation and transcriptional activation of Nrf2 both with and without UVA irradiation, and increased the expression of HO-1 and SOD (ref. ${ }^{173}$ ).

\section{Carnosic acid}

Carnosic acid (CAR, (4aR,10aS)-5,6-dihydroxy-1,1dimethyl-7-propan-2-yl-2,3,4,9,10,10a-hexahydrophenanthrene-4a-carboxylic acid) also called salvia or sage, is a phenolic diterpene (Fig. 2) found mainly in salvia (Salvia officinalis L.) and rosemary (Rosmarinus officinalis L.) from the Lamiaceae family. Several studies have demonstrated diverse biological effects of CAR that include anti-inflammatory, anticancer, hepatoprotective and anti-adipogenic activities. CAR is also widely used as a cosmetic and dental hygiene ingredient due to its strong antioxidant and antimicrobial properties ${ }^{174}$. CAR also has UVB protective potential ${ }^{175}$.

The pre-treatment of NHDF with CAR suppressed the MMP-1 mRNA elevation stimulated by UVA irradiation ${ }^{176}$. In UVA-exposed Hs68 human skin fibroblasts, CAR not only reduced the mRNA expression of MMP-1, but also of MMP-3 and MMP-9 (ref. ${ }^{175}$ ).

\section{Ursolic acid}

Ursolic acid (UA, 3- $\beta$-hydroxyurs-12-en-28-oic acid) is a lipophilic pentacyclic triterpenoid carboxylic acid (Fig. 2). UA is the major component of some fruits and traditional medicinal herbs e.g., apple peels, blueberry (Vaccinium spp.), cranberry (Vaccinium macrocarpon), heather flower (Calluna vulgaris), labrador tea (Ledum groenlandicum Retzius), olive (Olea europaea), pear (Pyrus pyrifolia), basil (Ocimum basilicum), thyme (Thymus), oregano (Origanum vulgare), sage (Salvia officinalis L.) or rosemary (Rosmarinus officinalis L.). UA exerts various biological effects, including anti-inflammatory, anti-atherosclerosis and anticancer. UA also reduces ROS level and increases the activity of antioxidant enzymes ${ }^{177}$. The pre-treatment of HaCaT with UA decreased UVAinduced ROS production, lipid peroxidation, activity and the protein level of MMP-2 and p53 (ref. ${ }^{178}$ ).

\section{Asiatic acid}

Asiatic acid (AA, 2 $\alpha, 23$-dihydroxyursolic acid), also known as dammarolic acid, is a pentacyclic triterpenoid (Fig. 2). It is abundantly present in many edible and medicinal plants including Centella asiatica, which is a renowned herb in many traditional medicine formulations ${ }^{175}$. The herb grows in the tropical regions of Asia, Oceania, Africa and America. In traditional Asian medicine, the herb has been used for hundreds of years to improve the healing of small wounds, scratches, burns, and hypertrophic wounds. Previous studies demonstrated that AA could be also used for wound healing and various dermal applications ${ }^{180,181}$. AA exhibited numerous pharmacological activities such as antioxidant, anti-inflammatory, hepatoprotective, cardioprotective, neuroprotective, and anticancer properties ${ }^{179}$. The pre-treatment of HaCaT 
with AA decreased UVA-induced ROS production, lipid peroxidation, MMP-2 activity and protein level and p53 protein expression ${ }^{178}$.

\section{Zerumbone}

Zerumbone (ZER, (2E,6E,10E)- 2,6,9,9-tetramethyl2,6,10-cycloundecatrien-1-one), a monocyclic sesquiterpene with three double bonds (Fig. 2), is obtained from Zingiber zerumbet Smith (Zingiberaceae). Its rhizomes are the richest in ZER, followed by the leaves. ZER has various biomedical properties. Several studies have shown its selective anti-proliferative effect on various cancer cells (e.g., colon, breast, cervix, and liver). ZER also exhibits antioxidant, anti-inflammatory, immunomodulatory or antimicrobial activity ${ }^{182}$. ZER was also demonstrated to prevent chemically-induced tumour initiation and promotion in mouse skin ${ }^{183}$.

ZER pre-treatment substantially suppressed UVAinduced $\mathrm{HaCaT}$ cell death and LDH release, ROS production, DNA single-strand breaks, DNA fragmentation and a dysregulated Bax/Bcl-2 ratio. ZER cytoprotective properties were associated with an increased nuclear translocation of Nrf2 and elevated ARE luciferase activity. The activation of Nrf2/ARE signalling was accompanied by the induction of HO-1 and $\gamma$-GCL catalytic subunit genes. ZER-induced Nrf2 transcriptional activation was mediated by the p38 MAPK, phosphoinositide 3-kinase/protein kinase B (AKT) and PKC signalling cascades. In the UVA-treated skin of nude mice, ZER pre-treatment significantly ameliorated UVA cytotoxicity via increased nuclear Nrf2 translocation and Nrf2-dependent antioxidant gene expression (HO-1 and $\gamma$-GCL catalytic subunit) (ref. ${ }^{184}$ ).

\section{beta-Carotene}

$\beta$-Carotene ( $\beta$-CAR) is a tetraterpenoid that consists of eight isoprene units ( 40 carbon atoms) in a core structure of conjugated double bonds substituted with two $\beta$-ionone rings (Fig. 2). $\beta$-CAR is a strongly red-orange pigment that occurs in many different fruits and vegetables such as mango, papaya, orange, apricot, watermelon, cantaloupe, pumpkin, carrot, red pepper, tomato and sweet potato. The colour of $\beta$-CAR in some bright green leafy vegetables is masked by chlorophyll, e.g. in spinach, kale, lettuce, broccoli or cabbage ${ }^{185,186}$. A number of studies investigated the effect of $\beta$-CAR on the prevention of solar erythema formation with contradictory results. The literature analysis implies that doses of about $10 \mathrm{mg} /$ day are required to provide UVB photoprotection ${ }^{186}$.

As for UVA radiation, $\beta$-CAR inhibits JNK activation and the mRNA and protein expression of TNF- $\alpha$, IL-1 $\beta$, and IL-10 in UVA-exposed $\mathrm{HaCaT}\left(\right.$ ref. $^{187}$ ). In the same cells, $\beta$-CAR suppressed the UVA-induced mRNA level of MMP-1, MMP-3, and MMP-10, three major MMPs involved in photoaging ${ }^{188}$. Microarray analysis in irradiated HaCaT showed that $\beta$-CAR inhibited UVA-induced extracellular matrix degradation and enhanced UVA-stimulated tanning-associated protease-activated receptor 2 (ref. $\left.{ }^{189}\right)$. The application of $\beta$-CAR to NHDF reduced the level of mtDNA mutagenesis provoked by repeated UVA expo- sure $^{190}$. $\beta$-CAR pre-treatment resulted in suppression of the UVA-induced transcriptional activation of HO-1 in normal human FEK4 fibroblasts ${ }^{191}$ and induced the mRNA and protein level of pro-inflammatory IL-6 as well as the protein level of HO-1 in human skin HFP-1 fibroblasts ${ }^{192}$. The application of -CAR to rat kidney fibroblasts prior to UVA exposure significantly increased the activities of CAT and SOD, while the level of TBARS was reduced ${ }^{193}$.

On the other hand, the pre-treatment of $\mathrm{C} 3 \mathrm{H} 10 \mathrm{~T} 1 / 2 \mathrm{fi}-$ broblasts with $\beta$-CAR increased UVA-induced DNA damage. The combination of $\beta$-CAR with flavonoids (naringin $>\mathrm{RU}>\mathrm{QE}$ ) significantly suppressed the photo-oxidative effect of $\beta$-CAR (ref. ${ }^{118}$ ). In another study, $\beta$-CAR increased membrane damage, stimulated HO-1 expression and induced caspase-3 activity in NHDF exposed to UVA light ${ }^{194}$. Similarly, in UVA-irradiated HFP-1 fibroblasts, $\beta$-CAR pre-treatment strongly enhanced HO-1 mRNA and protein expression. The level of this oxidative stress marker was suppressed by the concomitant addition of vitamin E, but only moderately by vitamin C (ref. ${ }^{195}$ ). These effects may be associated with the photodecomposition of $\beta$-CAR stimulated by UVA radiation that was shown in vitro. The rapid decomposition of $\beta$-CAR was further accelerated by sulphide and reduced by radical scavengers (dithiothreitol, thiourea) (ref. $\left.{ }^{196}\right)$.

\section{Astaxanthin}

Astaxanthin (AST, 3'3-dihydroxy- $\beta, \beta$-carotene-4,4'dione) is a red-orange lipophilic xanthophyll carotenoid, which is structurally similar to $\beta$-CAR but possesses an additional hydroxyl and ketone group on each $\beta$-ionone ring (Fig. 2). AST is a ubiquitous secondary metabolite naturally synthesized by a number of plants as well as bacteria, yeasts, microalgae crustaceans and salmonids. The commercial production of AST has traditionally been by chemical synthesis, but the microalga Haematococcus pluvialis seems to be the most promising source for its industrial biological production. AST has several essential biological functions in marine animals, including pigmentation, stress tolerance, reproductive capacity, protection against UV light effects, immune response and protection against the oxidation of macromolecules. From several studies including clinical trials, beneficial effects of AST on skin physiology and pathology are well documented including antioxidant, anti-inflammatory and UVB photoprotective action ${ }^{197}$.

The pre-treatment of NHDF with AST reduced the disruption of cell membrane integrity, level of intracellular ROS, amount of TBARS, number of apoptotic cells as well as the activity of caspase-3. AST also counteracted the decrease in CAT and SOD activity and reduced the mRNA and protein level of HO-1. The application of AST to rat kidney fibroblasts before UVA irradiation increased the activities of CAT and SOD and reduced the level of TBARS. AST was much more effective than the other carotenoids ( $\beta$-CAR and lutein) (ref. ${ }^{193}$ ). AST also reduced oxidative DNA damage to human neuroblastoma and rat trachea epithelial cells exposed to UVA radiation ${ }^{198}$. Synthetic AST and an algal extract (14\% of AST) de- 
creased UVA-induced DNA alterations to 1BR-3 human skin fibroblasts, a human melanocyte cell line and human intestinal $\mathrm{CaCo}-2$ cells. The algal extract exhibited a comparable UVA protection to $10 \mu \mathrm{M}$ AST on all three of the above cell types. Further, in 1BR-3 cells, the synthetic AST and algal extract prevented UVA-induced alterations to SOD activity and GSH content. Similarly, AST and the extract prevented the depletion of GSH in $\mathrm{CaCo}-2$ cells ${ }^{199}$. The addition of AST to NHDF immediately after UVA exposure significantly attenuated the induction of MMP-1 and neutral endopeptidase expression at the gene and protein level as well as reducing MMP-1 and skin fibroblast elastase activity and IL-6 secretion ${ }^{200}$. Dietary AST reduced features of chronic UVA exposure such as TEWL and wrinkle formation in female hairless mice. AST treatment also reduced the mRNA level of epidermal (lympho-epithelial Kazal-type related inhibitor, steroid sulfatase and aquaporin 3) and dermal (MMP-13) markers increased by chronic UVA irradiation ${ }^{201}$.

\section{Lycopene}

Lycopene (LY, (6E,8E,10E,12E,14E,16E,18E,20E,22 E,24E,26E)-2,6,10,14,19,23,27,31-octamethyldotriaconta$2,6,8,10,12,14,16,18,20,22,24,26,30$-tridecaene) is a bright red linear unsaturated tetraterpene composed of eight isoprene units (Fig. 2). The major sources for LY are tomatoes and tomato products, although red carrot, apricot, papaya, pink grapefruit, guava and watermelon also contain LY in considerable amounts ${ }^{202}$. The pharmacological properties of LY are linked mainly to its antioxidant activity that was demonstrated in many in vitro, ex vivo and in vivo studies ${ }^{186}$.

In a placebo-controlled, double-blind, randomized crossover study, the oral treatment of healthy volunteers with LY-rich tomato nutrient complex inhibited UVA1 (340-400 nm) and UVA/B induced the upregulation of HO-1, intercellular adhesion molecule 1 (ICAM-1) and MMP-1 mRNA level ${ }^{203}$.

On the other hand, LY enrichment enhanced UVAinduced HO-1 expression and strongly induced DNA damage in UVA-irradiated C3H10T1/2 mouse embryo fibroblasts $^{204}$. Similarly, LY pre-treatment of NHDF potentiated the UVA-induced elevation of MMP-1 and HO-1 mRNA levels ${ }^{176}$.

\section{Lutein}

Lutein (LT, 4-[18-(4-hydroxy-2,6,6-trimethyl-1cyclohexenyl)-3,7,12,16-tetramethyloctadeca-1,3,5,7, 9,11,13, 15,17-nonaenyl]-3,5,5-trimethyl-cyclohex-2-en-1-ol or (3R,3'R,6R)-4,5-didehydro-5,6-dihydro- $\beta$, $\beta$-carotene$3,3^{\prime}$-diol) is a member of the xanthophyll family of carotenoids containing hydroxyl groups that make LT more polar than carotenoids, such as LY and $\beta$-CAR (Fig. 2). LT is widespread in nature, abundantly present in leafy green vegetables such as spinach, lettuce and kale, but also in apricot, cucumber or red pepper ${ }^{188}$. LT is highly concentrated in the human retina and is responsible for central vision and high visual acuity. LT is the second most prevalent carotenoid in human serum. LT is also found in significant quantities in human skin ${ }^{205}$. The biological effects of LT are linked to its ability to filter the high-energy wavelengths of visible light and to protect against ROS formation. Animal studies have provided evidence of significant efficacy against light-induced skin damage ${ }^{206}$. The oral and topical administration of LT provides multiple benefits to the human $\operatorname{skin}^{207}$.

The application of LT to rat kidney fibroblasts prior to UVA exposure protected the cells against UVA-induced decrease in CAT and SOD and increase in TBARS level ${ }^{193}$. LT also reduced oxidative DNA damage in human neuroblastoma and rat trachea epithelial cells exposed to UVA radiation ${ }^{198}$. In a placebo-controlled, double-blind, randomized crossover study, the oral treatment of healthy volunteers with LT completely inhibited UVA1 (340-400 nm) and UVA/B induced the mRNA upregulation of HO-1, ICAM-1 and MMP-1 ( ref. $^{203}$ ).

\section{Zeaxantin}

Zeaxantin (ZEA, 4-[18-(4-hydroxy-2,6,6-trimethyl-1-cyclohexenyl)-3, 7,12,16-tetramethyl-octadeca$1,3,5,7,9,11,13,15,17$-nonaenyl]-3,5,5-trimethyl-cyclohex-3-en-1-ol or ( $\left.3 \mathrm{R}, 3^{\prime} \mathrm{R}\right)-\beta, \beta$-carotene-3,3'-diol) is another member of the xanthophyll family of carotenoids. ZEA is isomeric with LT, differing only in the localization of one double bond (Fig. 2). ZEA is present in high concentrations in green leafy vegetables such as spinach and kale, but also in others e.g., green pepper, corn or wolfberries. Like LT, ZEA is also highly concentrated in the human retina. ZEA is also found in significant quantities in human skin. ZEA works as a filter of the blue light wavelengths and as an antioxidant ${ }^{186,206}$. Topical and oral treatment with ZEA provides multiple benefits to the human skin ${ }^{207,208}$. Dietary ZEA supplementation also protects the skin against UVB-induced photoaging and photocarcinogenesis in mice ${ }^{209}$.

The application of ZEA reduced oxidative DNA damage in human neuroblastoma and rat trachea epithelial cells exposed to UVA radiation ${ }^{198}$.

On the other hand, the rapid decomposition of ZEA stimulated by UVA radiation was demonstrated in vitro. The photodecomposition of ZEA was more rapid than that of $\beta$-CAR due to the presence of hydroxyl groups. The decomposition was accelerated by sulphide and reduced in the presence of dithiothreitol or thiourea ${ }^{196}$.

\section{L-Ergothioneine}

The low-molecular-weight thiol-based antioxidant L-ergothioneine (EGT, 2-mercaptohistidinetrimethylbetaine) is a derivative of the amino acid histidine. EGT has two functional groups: an L-thiol $(\mathrm{SH})$ group and a quaternary ammonium group $\mathrm{N}^{+}-\left(\mathrm{CH}_{3}\right)_{3}$ (Fig. 2). Despite apparently being exclusively synthesized in fungi, cyanobacteria and mycobacteria, EGT is ubiquitously present in most cells and the tissues of plants and mammals. Some foods were found to possess particularly high levels of EGT, for example certain species of mushrooms, black and red beans, red meat, liver, kidney and grains. Numerous in vitro assays have demonstrated the antioxi- 
dant and cytoprotective capabilities of EGT against a wide range of cellular stressors, including UV and gamma radiation $^{210}$.

In UVA-exposed NHDF, EGT reduced the protein and mRNA level of MMP-1 (ref. ${ }^{211}$ ). The EGT treatment of HaCaT prior to UVA exposure significantly prevented LDH leakage into the medium. UVA-induced ROS formation and DNA oxidative damage was remarkably suppressed by EGT, with a parallel inhibition of apoptosis. Furthermore, EGT alleviated UVA-induced mitochondrial dysfunction. A dose-dependent increase in the antioxidant proteins HO-1, NQO-1 and $\gamma$-GCL, and reduced GSH produced by EGT was associated with an upregulated Nrf2 and downregulated Keap-1 level ${ }^{212}$. EGT enhanced the level of reduced GSH and protected NHDF from the induction of photoaging-associated mtDNA damage (mutation and deletion) (ref. $\left.{ }^{213}\right)$.

\section{CONCLUSION}

The exposure of human skin to solar radiation intensifies skin aging commonly known as photoaging and escalates the probability of developing skin cancer. Although skin protection against solar radiation has been studied for decades, research was focused on UVB, and UVA was mostly ignored. The plant kingdom represents the main conventional source of new candidates with photoprotective activity. In this review, phytochemicals and plant extracts with UVA-protective potency are summarized. As documented, there is a range of phytochemicals that possess UVA protective properties, many of them also protect against UVB photons and thus may be useful in the protection and treatment of UV light-caused damage; alone or in combination with traditional UV filters. However, most of the compounds and extracts listed in this review were only tested in very simple in vitro or possibly ex vivo systems. This fact results from the prohibition of animal use for this purpose in many countries around the world. The safety of new photoprotective phytochemicals may be based on their long-term use in traditional medicine. However, clinical trials are needed to validate the effectiveness of new candidates for photoprotective preparations. The demanding nature and ethical limits of studies on human volunteers is most likely the most restrictive step in the rapid introduction of new photoprotective agents for practical use.

\section{Search strategy and selection criteria}

The aim of our research strategy was to evaluate well documented studies on the UVA photoprotective properties of phytochemicals and plant extracts. The articles from 1998 to 2019 were searched using the PubMed and Web of Science databases. All searches were up-to-date since January 2020. The search terms used included "UVA photoprotection", "UVA protection”, "plant and UVA protection”, "polyphenols and UVA protection”. Only articles in English were reviewed.

\section{ABBREVIATIONS}

AA, Asiatic acid; AKT, Protein kinase B; AP, Apigenin; ARE, Antioxidant responsible element; AST, Astaxanthin; BE, Bilberry extract; $\beta$-CAR, $\beta$-Carotene; CA, Caffeic acid; CAR, Carnosic acid; CAT, Catalase; $C G$, Chrysanthemin; $\mathrm{CH}$, Chrysin; CIN, Cinnamic acid; COX2, Cyclooxygenase 2; CPD, Cyclobutane-pyrimidine dimers; CUR, Curcumin; DHM, Dihydromyricetin; DHSB, 2,3-Dehydrosilybin; EA, Ellagic acid; EC, (-)-epicatechin, ECG, (-)-epicatechin-3-gallate, (-)-epigallocatechin; EGCG, (-)-epigallocatechin-3-gallate; ERK, Extracellular signal-regulated kinases; EGT, L-Ergothioneine; FA, Ferulic acid; $\gamma$-GCL, $\gamma$-Glutamate-L-cysteine ligase; GE, Genistein; GPx, Glutathione peroxidase; GSH, Glutathione; GSR, Glutathione reductase; GSSG, Oxidized glutathione; GST, Glutathione S-transferase; HaCaT, Spontaneously transformed aneuploid immortal human skin keratinocyte cell line; NHDF, Normal human dermal fibroblasts; HE, Hesperidin; 4-HNE, 4-Hydroxynonenal; HO-1, Heme oxygenase-1; HPRT, Hypoxanthine-guanine phosphoribosyl transferase; HSP 70, Heat shock protein 70; ICAM-1, Intercellular adhesion molecule 1; IL-6, Interleukin-6; ISB, Isosilybin; JNK, c-Jun N-terminal kinase 1/2; Keap1, Kelch-like ECH-associated protein 1; Ki-67, Protein associated with cellular proliferation and ribosomal RNA transcription; LDH, Lactate dehydrogenase; LT, Lutein; LU, Luteolin; LY, Lycopene; MMP, Matrix metalloproteinases; MAPK, Mitogenactivated protein kinases; MDA, Malondialdehyde; MeOEC, 3'-O-Methyl epicatechin; MMP-1, Collagenase; MMP-3, Stromelysin; MMP-9, Gelatinase; mTOR, Serine-threonine kinase involved in cell growth; NF$\kappa \mathrm{B}$, Nuclear factor kappa B; NQO1, NADPH quinone oxidoreductase-1; NHEK, Normal human epidermal keratinocytes; Nrf2, Nuclear factor erythroid-2 related factor 2; 8-OH-dG, 8-Hydroxydeoxyguanine; oxyRE, Oxyresveratrol; PCNA, Proliferating cell nuclear antigen; PKC, Protein kinase C; QE, Quercetin; RA, Rosmarinic acid; RE, Resveratrol; RNS, Reactive nitrogen species; ROS, Reactive oxygen species; RPE, Retinal pigment epithelial cells; RU, Rutin; SB, Silybin; SC, Silychristin; SD, Silydianin; SM, Silymarin; SOD, Superoxide dismutase; TBARS, Thiobarbituric acid reactive substances; Trx, Thioredoxin; TEWL, Transepidermal water loss; TIMP-1, Tissue inhibitors of MMP-1; TIMP-2, Tissue inhibitors of MMP-2; TNF- $\alpha$, Tumour necrosis factor alpha; TrxR, Trx reductase; UA, Ursolic acid; UV, Ultraviolet; ZEA, Zeaxantin; ZER, Zerumbone.

Acknowledgements: This work was financially supported by the grant IGA_LF_2019_015, IGA_LF_2020_022 and the Institutional Support of Palacký University in Olomouc - RVO 61989592.

Author contributions: ARS, DS: literature search and manuscript writing; JV, ARS: critical reading and manuscript revision.

Conflict of interest statement: The authors state that there are no conflicts of interest regarding the publication of this article. 


\section{REFERENCES}

1. Svobodová A, Vostálová J. Solar radiation induced skin damage: review of protective and preventive options. Int J Radiat Biol 2010;86(12):999-1030. doi: 10.3109/09553002.2010.501842

2. McDaniel D, Farris $P$, Valacchi G. Atmospheric skin aging-Contributors and inhibitors. J Cosmet Dermatol 2018;17(2):124-37. doi: 10.1111/ jocd. 12518

3. Karran P, Brem R. Protein oxidation, UVA and human DNA repair. DNA Repair (Amst) 2016;44:178-85. doi: 10.1016/j.dnarep.2016.05.024

4. McMillan TJ, Leatherman E, Ridley A, Shorrocks J, Tobi SE, Whiteside JR. Cellular effects of long wavelength UV light (UVA) in mammalian cells. J Pharm Pharmacol 2008;60(8):969-76. doi: 10.1211/ jpp.60.8.0004

5. Cockell CS, Knowland J. Ultraviolet radiation screening compounds. Biol Rev Camb Philos Soc 1999;74(3):311-45.

6. Nichols JA, Katiyar SK. Skin photoprotection by natural polyphenols: anti-inflammatory, antioxidant and DNA repair mechanisms. Arch Dermatol Res 2010;302(2):71-83. doi: 10.1007/s00403-009-1001-3

7. Sharma P, Montes de Oca MK, Alkeswani AR, McClees SF, Das T, Elmets CA, Afaq F. Tea polyphenols for the prevention of UVBinduced skin cancer. Photodermatol Photoimmunol Photomed 2018;34(1):50-9. doi: 10.1111/phpp.12356

8. Tobi SE, Gilbert M, Paul N, McMillan TJ. The green tea polyphenol, epigallocatechin-3-gallate, protects against the oxidative cellular and genotoxic damage of UVA radiation. Int J Cancer 2002;102(5):439-44.

9. Xia J, Song X, Bi Z, Chu W, Wan Y. UV-induced NF-kappaB activation and expression of IL- 6 is attenuated by (-)-epigallocatechin3-gallate in cultured human keratinocytes in vitro. Int J Mol Med 2005; 16(5):943-50.

10. Song XZ, Xia JP, Bi ZG. Effects of (-)-epigallocatechin-3-gallate on expression of matrix metalloproteinase- 1 and tissue inhibitor of metalloproteinase- 1 in fibroblasts irradiated with ultraviolet $A$. Chin Med J (Engl) 2004;117(12):1838-41.

11. Zhu J, Luo D, Shen $\mathrm{CH}, \mathrm{Xu}$ J. Photo-protection of epigallocatechin3-gallate on aging and gene mutation of human skin fibroblasts caused by ultraviolet radiation: an in vitro experiment. Zhonghua Yi Xue Za Zhi 2007;87(20):1398-401.

12. Chan $\mathrm{CM}$, Huang $\mathrm{JH}$, Lin $\mathrm{HH}$, Chiang $\mathrm{HS}$, Chen $\mathrm{BH}$, Hong JY, Hung CF. Protective effects of (-)-epigallocatechin gallate on UVA-induced damage in ARPE19 cells. Mol Vis 2008;14:2528-34.

13. Sevin A, Oztaş P, Senen D, Han U, Karaman C, Tarimci N, Kartal M, Erdoğan B. Effects of polyphenols on skin damage due to ultraviolet A rays: an experimental study on rats. J Eur Acad Dermatol Venereol 2007;21(5):650-6.

14. Kim J, Hwang JS, Cho YK, Han Y, Jeon YJ, Yang KH. Protective effects of (-)-epigallocatechin-3-gallate on UVA- and UVB-induced skin damage. Skin Pharmacol Appl Skin Physiol 2001;14(1):11-9.

15. Soriani M, Rice-Evans C, Tyrrell RM. Modulation of the UVA activation of haem oxygenase, collagenase and cyclooxygenase gene expression by epigallocatechin in human skin cells. FEBS Lett 1998;439(3):253-7.

16. Huang CC, Fang JY, Wu WB, Chiang HS, Wei YJ, Hung CF. Protective effects of (-)-epicatechin-3-gallate on UVA-induced damage in $\mathrm{HaCaT}$ keratinocytes. Arch Dermatol Res 2005;296(10):473-81.

17. Basu-Modak S, Gordon MJ, Dobson LH, Spencer JP, Rice-Evans C, Tyrrell RM. Epicatechin and its methylated metabolite attenuate UVA-induced oxidative damage to human skin fibroblasts. Free Radic Biol Med 2003;35(8):910-21.

18. Basu-Modak S, Ali D, Gordon M, Polte T, Yiakouvaki A, Pourzand C, Rice-Evans C, Tyrrell RM. Suppression of UVA-mediated release of labile iron by epicatechin--a link to lysosomal protection. Free Radic Biol Med 2006;41(8):1197-204.

19. Harwansh RK, Mukherjee PK, Kar A, Bahadur S, Al-Dhabi NA Duraipandiyan V. Enhancement of photoprotection potential of catechin loaded nanoemulsion gel against UVA induced oxidative stress. J Photochem Photobiol B 2016;160:318-29. doi: 10.1016/j. jphotobiol.2016.03.026

20. Šimánek V, Křen V, Ulrichová J, Vičar J, Cvak L. Silymarin: What is in the name...? An appeal for a change of editorial policy. Hepatology 2000;32(2):442-4

21. Vaid M, Katiyar SK. Molecular mechanisms of inhibition of photocarcinogenesis by silymarin, a phytochemical from milk thistle (Silybum marianum L. Gaertn.) (Review). Int J Oncol 2010;36(5):1053-60.
22. Montes de Oca MK, Pearlman RL, McClees SF, Strickland R, Afaq F. Phytochemicals for the Prevention of Photocarcinogenesis. Photochem Photobiol 2017;93(4):956-74. doi: 10.1111/php.12711

23. Rajnochová Svobodová A, Gabrielová E, Michaelides L, Kosina P, Ryšavá A, Ulrichová J, Zálešák B, Vostálová J. UVA-photoprotective potential of silymarin and silybin. Arch Dermatol Res 2018;310(5):413-24. doi: 10.1007/s00403-018-1828-6

24. Rajnochová Svobodová A, Gabrielová E, Ulrichová J, Zálešák B, Biedermann D, Vostálová J. A pilot study of the UVA-photoprotective potential of dehydrosilybin, isosilybin, silychristin, and silydianin on human dermal fibroblasts. Arch Dermatol Res 2019;311(6):477-490. doi: 10.1007/s00403-019-01928-7

25. Svobodová A, Zdařilová A, Mališková J, Mikulková $H$, Walterová $D$, Vostálová J. Attenuation of UVA-induced damage to human keratinocytes by silymarin. J Dermatol Sci 2007;46(1):21-30.

26. Svobodová A, Zdařilová A, Walterová D, Vostálová J. Flavonolignans from Silybum marianum moderate UVA-induced oxidative damage to HaCaT keratinocytes. J Dermatol Sci 2007;48(3):213-24.

27. Fidrus $E$, Ujhelyi $Z$, Fehér $P$, Hegedűs $C$, Janka $E A$, Paragh $G$, Vasas G, Bácskay I, Remenyik É. Silymarin: Friend or Foe of UV Exposed Keratinocytes? Molecules 2019;24(9). pii: E1652. doi: 10.3390/molecules24091652

28. Narayanapillai S, Agarwal C, Tilley C, Agarwal R. Silibinin is a potent sensitizer of UVA radiation-induced oxidative stress and apoptosis in human keratinocyte $\mathrm{HaCaT}$ cells. Photochem Photobiol 2012;88(5):1135-40. doi: 10.1111/j.1751-1097.2011.01050

29. Rajnochová Svobodová A, Zálešák B, Biedermann D, Ulrichová J, Vostálová J. Phototoxic potential of silymarin and its bioactive components. J Photochem Photobiol B 2016;156:61-8. doi: 10.1016/j. jphotobiol.2016.01.011

30. Khwairakpam AD, Bordoloi D, Thakur KK, Monisha J, Arfuso F, Sethi G, Mishra S, Kumar AP, Kunnumakkara AB. Possible use of Punica granatum (Pomegranate) in cancer therapy. Pharmacol Res 2018;133:5364. doi: 10.1016/j.phrs.2018.04.021

31. Pacheco-Palencia LA, Noratto G, Hingorani L, Talcott ST, MertensTalcott SU. Protective effects of standardized pomegranate (Punica granatum L.) polyphenolic extract in ultraviolet-irradiated human skin fibroblasts. J Agric Food Chem 2008;56(18):8434-41. doi: 10.1021/jf8005307

32. Kang SJ, Choi BR, Kim SH, Yi HY, Park HR, Park SJ, Song CH, Park JH, Lee $Y J$, Kwang $S$. Inhibitory effects of pomegranate concentrated solution on the activities of hyaluronidase, tyrosinase, and metalloproteinase. J Cosmet Sci 2015;66(3):145-59.

33. Syed DN, Malik A, Hadi N, Sarfaraz S, Afaq F, Mukhtar H. Photochemopreventive effect of pomegranate fruit extract on UVA-mediated activation of cellular pathways in normal human epidermal keratinocytes. Photochem Photobiol 2006;82(2):398-405.

34. Parrado C, Mascaraque M, Gilaberte Y, Juarranz A, Gonzalez S. Fernblock (Polypodium leucotomos Extract): Molecular Mechanisms and Pleiotropic Effects in Light-Related Skin Conditions, Photoaging and Skin Cancers, a Review. Int J Mol Sci 2016;17(7). pii: E1026. doi: 10.3390/ijms17071026

35. Berman B, Ellis C, Elmets C. Polypodium Leucotomos--An Overview of Basic Investigative Findings. J Drugs Dermatol 2016;15(2):224-8

36. Palomino OM. Current knowledge in Polypodium leucotomos effect on skin protection. Arch Dermatol Res 2015;307(3):199-209. doi: 10.1007/s00403-014-1535-x

37. Alonso-Lebrero JL, Domínguez-Jiménez $C$, Tejedor $R$, Brieva $A$ Pivel JP. Photoprotective properties of a hydrophilic extract of the fern Polypodium leucotomos on human skin cells. J Photochem Photobiol B 2003;70(1):31-7.

38. Philips N, Conte J, Chen YJ, Natrajan P, Taw M, Keller T, Givant J, Tuason M, Dulaj L, Leonardi D, Gonzalez S. Beneficial regulation of matrix metalloproteinases and their inhibitors, fibrillar collagens and transforming growth factor-beta by Polypodium leucotomos, directly or in dermal fibroblasts, ultraviolet radiated fibroblasts, and melanoma cells. Arch Dermatol Res 2009;301(7):487-95. doi: 10.1007/s00403-009-0950-x

39. Mulero $M$, Rodríguez-Yanes $E$, Nogués $M R$, Giralt $M$, Romeu $M$ González S, Mallol J. Polypodium leucotomos extract inhibits glutathione oxidation and prevents Langerhans cell depletion induced by UVB/UVA radiation in a hairless rat model. Exp Dermatol 2008;17(8):653-8. doi: 10.1111/j.1600-0625.2007.00684.x

40. Middelkamp-Hup MA, Pathak MA, Parrado C, Garcia-Caballero T, Rius-Díaz F, Fitzpatrick TB, González S. Orally administered 
Polypodium leucotomos extract decreases psoralen-UVA-induced phototoxicity, pigmentation, and damage of human skin. J Am Acad Dermatol 2004;50(1):41-9.

41. Smeriglio A, Monteleone D, Trombetta D. Health effects of Vaccinium myrtillus L.: evaluation of efficacy and technological strategies for preservation of active ingredients. Mini Rev Med Chem 2014;14(7):567-84

42. Yamaura K, Shimada M, Ueno K. Anthocyanins from bilberry (Vaccinium myrtillus L.) alleviate pruritus in a mouse model of chronic allergic contact dermatitis. Pharmacognosy Res 20111;3(3):173-7. doi: 10.4103/0974-8490.85002

43. Svobodová A, Zdařilová A, Vostálová J. Lonicera caerulea and Vaccinium myrtillus fruit polyphenols protect $\mathrm{HaCaT}$ keratinocytes against UVB-induced phototoxic stress and DNA damage. J Dermatol Sci 2009;56(3):196-204. doi: 10.1016/j.jdermsci.2009.08.004

44. Svobodová A, Rambousková J, Walterová D, Vostálová J. Bilberry extract reduces UVA-induced oxidative stress in HaCaT keratinocytes: a pilot study. Biofactors 2008;33(4):249-66.

45. Calò R, Marabini L. Protective effect of Vaccinium myrtillus extract against UVA- and UVB-induced damage in a human keratinocyte cell line (HaCaT cells). J Photochem Photobiol B 2014;132:27-35. doi: 10.1016/j.jphotobiol.2014.01.013

46. Bucci P, Prieto MJ, Milla L, Calienni MN, Martinez L, Rivarola V, Alonso S, Montanari J. Skin penetration and UV-damage prevention by nanoberries. J Cosmet Dermatol 2018;17(5):889-99. doi: 10.1111/ jocd. 12436

47. Švarcová I, Heinrich J, Valentová K. Berry fruits as a source of biologically active compounds: the case of Lonicera caerulea. Biomed Pap Med Fac Univ Palacky Olomouc Czech Repub 2007;151(2):163-74.

48. Rajnochová Svobodová A, Galandáková A, Palíková I, Doležal D, Kylarová D, Ulrichová J, Vostálová J. Effects of oral administration of Lonicera caerulea berries on UVB-induced damage in SKH-1 mice. A pilot study. Photochem Photobiol Sci 2013;12(10):1830-40. doi: 10.1039/c3pp50120e

49. Svobodová A, Rambousková J, Walterová D, Vostálová J. Protective effects of phenolic fraction of blue honeysuckle fruits against UVA-induced damage to human keratinocytes. Arch Dermatol Res 2008;300(5):225-33. doi: 10.1007/s00403-008-0850-5

50. Vostálová J, Galandáková A, Palíková I, Ulrichová J, Doležal D, Lichnovská R, Vrbková J, Rajnochová Svobodová A. Lonicera caerulea fruits reduce UVA-induced damage in hairless mice. J Photochem Photobiol B 2013;128:1-11. doi: 10.1016/j.jphotobiol.2013.07.024

51. Shabnum S, Wagay MG. Essential oil composition of Thymus Vulgaris L. and their uses. J. Research \& Development 2011;11:83-94.

52. El-Newary SA, Shaffie NM, Omer EA. The protection of Thymus vulgaris leaves alcoholic extract against hepatotoxicity of alcohol in rats. Asian Pac J Trop Med 2017;10(4):361-71. doi: 10.1016/j. apjtm.2017.03.023

53. Sun Z, Park SY, Hwang E, Zhang M, Seo SA, Lin P, Yi TH. Thymus vulgaris alleviates UVB irradiation induced skin damage via inhibition of MAPK/AP-1 and activation of Nrf2-ARE antioxidant system. J Cell Mol Med 2017;21(2):336-48. doi: 10.1111/jcmm.12968

54. Cornaghi L, Arnaboldi F, Calò R, Landoni F, Baruffaldi Preis WF, Marabini L, Donetti E. Effects of UV Rays and Thymol/Thymus vulgaris L. Extract in an ex vivo Human Skin Model: Morphological and Genotoxicological Assessment. Cells Tissues Organs 2016;201(3):180 92. doi: 10.1159/000444361

55. Calò R, Visone CM, Marabini L. Thymol and Thymus Vulgaris L. activity against UVA- and UVB-induced damage in NCTC 2544 cell line. Mutat Res Genet Toxicol Environ Mutagen 2015;791:30-7. doi: 10.1016/j. mrgentox.2015.07.009

56. El-Mostafa K, El Kharrassi Y, Badreddine A, Andreoletti P, Vamecq J, E Kebbaj MS, Latruffe N, Lizard G, Nasser B, Cherkaoui-Malki M. Nopa cactus (Opuntia ficus-indica) as a source of bioactive compounds for nutrition, health and disease. Molecules 2014;19(9):14879-901. doi: 10.3390/molecules 190914879

57. Petruk G, Di Lorenzo F, Imbimbo P, Silipo A, Bonina A, Rizza L, Piccol $\mathrm{R}$, Monti DM, Lanzetta R. Protective effect of Opuntia ficus-indica L. cladodes against UVA-induced oxidative stress in normal human keratinocytes. Bioorg Med Chem Lett 2017;27(24):5485-9. doi: 10.1016/j.bmcl.2017.10.043

58. Gupta RK, Patel AK. Do the health claims made for Morinda citrifolia (Noni) harmonize with current scientific knowledge and evaluation of its biological effects. Asian Pac J Cancer Prev 2013;14(8):4495-9.
59. West BJ, Deng S, Palu AK, Jensen CJ. Morinda citrifolia Linn. (Rubiaceae) leaf extracts mitigate UVB-induced erythema. J Nat Med 2009;63(3):351-4. doi: 10.1007/s11418-009-0327-7

60. Masuda M, Murata K, Naruto S, Uwaya A, Isami F, Matsuda H. Matrix metalloproteinase-1 inhibitory activities of Morinda citrifolia seed extract and its constituents in UVA-irradiated human dermal fibroblasts. Biol Pharm Bull 2012;35(2):210-5.

61. Hashemi SA, Madani SA, Abediankenari S. The Review on Properties of Aloe Vera in Healing of Cutaneous Wounds. Biomed Res Int 2015;2015:714216. doi: 10.1155/2015/714216

62. Rahman S, Carter P, Bhattarai N. Aloe Vera for Tissue Engineering Applications. J Funct Biomater 2017;8(1). pii: E6. doi: 10.3390/ jfb8010006

63. Saito M, Tanaka M, Misawa E, Yao R, Nabeshima K, Yamauchi K, Abe F, Yamamoto Y, Furukawa F. Oral administration of Aloe vera gel powder prevents UVB-induced decrease in skin elasticity via suppression of overexpression of MMPs in hairless mice. Biosci Biotechnol Biochem 2016;80(7):1416-24. doi: 10.1080/09168451.2016.1156480

64. Yao R, Tanaka M, Misawa E, Saito M, Nabeshima K, Yamauchi K, Abe F, Yamamoto Y, Furukawa F. Daily Ingestion of Aloe Vera Gel Powder Containing Aloe Sterols Prevents Skin Photoaging in OVX Hairless Mice. J Food Sci 2016;8(11):H2849-H28572. doi: 10.1111/17503841.13527

65. Misawa E, Tanaka M, Saito M, Nabeshima K, Yao R, Yamauchi K, Abe F, Yamamoto Y, Furukawa F. Protective effects of Aloe sterols against UVB-induced photoaging in hairless mice. Photodermatol Photoimmunol Photomed 2017;33(2):101-11. doi: 10.1111/ phpp.12286

66. Rodrigues D, Viotto AC, Checchia R, Gomide A, Severino D, Itri R, Baptista MS, Martins WK. Mechanism of Aloe Vera extract protection against UVA: shelter of lysosomal membrane avoids photodamage. Photochem Photobiol Sci 2016;15(3):334-50. doi: 10.1039/ c5pp00409h

67. Sałaga M, Lewandowska U, Sosnowska D, Zakrzewski PK Cygankiewicz Al, Piechota-Polańczyk A, Sobczak M, Mosinska P, Chen C, Krajewska WM, Fichna J. Polyphenol extract from evening primrose pomace alleviates experimental colitis after intracolonic and oral administration in mice. Naunyn Schmiedebergs Arch Pharmacol 2014;387(11):1069-78. doi: 10.1007/s00210-014-1025-x

68. Kiss AK, Derwińska M, Dawidowska A, Naruszewicz M. Novel biological properties of Oenothera paradoxa defatted seed extracts: effects on metallopeptidase activity. J Agric Food Chem 2008;56(17):784552.

69. Lewandowska U, Owczarek K, Szewczyk K, Podsędek A, Koziołkiewicz $M$, Hrabec $E$. Influence of polyphenol extract from evening primrose (Oenothera paradoxa) seeds on human prostate and breast cancer cell lines. Postepy Hig Med Dosw (Online) 2014;68:110-8. doi: 10.5604/17322693.1088036

70. Jaszewska E, Kośmider A, Kiss AK, Naruszewicz M. Pro-oxidative and pro-apoptotic action of defatted seeds of Oenothera paradoxa on human skin melanoma cells. J Agric Food Chem 2009;57(18):8282-9. doi: $10.1021 /$ jf901395t

71. Jaszewska E, Soin M, Filipek A, Naruszewicz M. UVA-induced ROS generation inhibition by Oenothera paradoxa defatted seeds extract and subsequent cell death in human dermal fibroblasts. J Photochem Photobiol B 2013;126:42-6. doi: 10.1016/j.jphotobiol.2013.07.001

72. Bazylko A, Borzym J, Parzonko A. Determination of in vitro antioxidant and UV-protecting activity of aqueous and ethanolic extracts from Galinsoga parviflora and Galinsoga quadriradiata herb. J Photochem Photobiol B 2015;149:189-95. doi: 10.1016/j.jphotobiol.2015.06.010

73. Parzonko A, Kiss AK. Caffeic acid derivatives isolated from Galinsoga parviflora herb protected human dermal fibroblasts from UVAradiation. Phytomedicine 2019;57:215-22. doi: 10.1016/j.phymed.2018.12.022

74. Gęgotek A, Jastrząb A, Jarocka-Karpowicz I, Muszyńska M, Skrzydlewska E. The Effect of Sea Buckthorn (Hippophae rhamnoides L.) Seed Oil on UV-Induced Changes in Lipid Metabolism of Human Skin Cells. Antioxidants (Basel) 2018;7(9). pii: E110. doi: 10.3390/antiox7090110

75. Atawodi SE, Pfundstein B, Haubner R, Spiegelhalder B, Bartsch H, Owen RW. Content of polyphenolic compounds in the Nigerian stimulants Cola nitida ssp. alba, Cola nitida ssp. rubra A. Chev, and 
Cola acuminata Schott \& Endl and their antioxidant capacity. J Agric Food Chem 2007;55(24):9824-8.

76. Franco R, Oñatibia-Astibia A, Martínez-Pinilla E. Health benefits of methylxanthines in cacao and chocolate. Nutrients 2013;5(10):415973. doi: 10.3390/nu5104159

77. Mitani H, Ryu A, Suzuki T, Yamashita M, Arakane K, Koide C. Topical application of plant extracts containing xanthine derivatives can prevent UV-induced wrinkle formation in hairless mice. Photodermatol Photoimmunol Photomed 2007;23(2-3):86-94.

78. Baharum Z, Akim AM, Hin TY, Hamid RA, Kasran R. Theobroma cacao: Review of the Extraction, Isolation, and Bioassay of Its Potential Anticancer Compounds. Trop Life Sci Res 2016;27(1):21-42.

79. Katz DL, Doughty K, Ali A. Cocoa and chocolate in human health and disease. Antioxid Redox Signal 2011;15(10):2779-811. doi: 10.1089/ ars.2010.3697

80. Tang $Y$, Tsao R. Phytochemicals in quinoa and amaranth grains and their antioxidant, anti-inflammatory, and potential health beneficial effects: a review. Mol Nutr Food Res 2017;61(7). doi: 10.1002/ mnfr.201600767

81. Wolosik K, Markowska A. Amaranthus Cruentus taxonomy, botanical description, and review of its seed chemical composition. Nat Prod Commun 2019;14(5):1-10. doi: 10.1177/1934578X19844141

82. Wolosik K, Zareba I, Surazynski A, Markowska A. The Possible Preand Post-UVA Radiation Protective Effect of Amaranth Oil on Human Skin Fibroblast Cells. Pharmacogn Mag 2017;13(Suppl 2):S339-S343. doi: 10.4103/pm.pm_522_15

83. Zduńska K, Dana A, Kolodziejczak A, Rotsztejn H. Antioxidant Properties of Ferulic Acid and Its Possible Application. Skin Pharmacol Physiol 2018;31(6):332-6. doi: 10.1159/000491755

84. Kumar N, Pruthi V. Potential applications of ferulic acid from natural sources. Biotechnol Rep (Amst) 2014;4:86-93. doi: 10.1016/j. btre.2014.09.002

85. Ambothi K, Prasad NR, Balupillai A Ferulic acid inhibits UVB-radiation induced photocarcinogenesis through modulating inflammatory and apoptotic signaling in Swiss albino mice. Food Chem Toxico 2015;82:72-8. doi: 10.1016/j.fct.2015.04.031

86. Burns EM, Tober KL, Riggenbach JA, Kusewitt DF, Young GS, Oberyszyn TM. Differential effects of topical vitamin E and C E Ferulic ${ }^{\oplus}$ treatments on ultraviolet light B-induced cutaneous tumor development in Skh-1 mice. PLoS One 2013;8(5):e63809. doi: 10.1371/journal.pone.0063809

87. Wu Y, Zheng $X, X u X G$, Li YH, Wang B, Gao XH, Chen HD, Yatskayer $M$, Oresajo $C$. Protective effects of a topical antioxidant complex containing vitamins $C$ and $E$ and ferulic acid against ultraviolet irradiation-induced photodamage in Chinese women. J Drugs Dermatol 2013;12(4):464-8.

88. Chaiprasongsuk A, Onkoksoong T, Pluemsamran T, Limsaengura $\mathrm{S}$, Panich U. Photoprotection by dietary phenolics against melanogenesis induced by UVA through Nrf2-dependent antioxidant responses. Redox Biol 2016;8:79-90. doi: 10.1016/j.redox.2015.12.006

89. Pluemsamran T, Onkoksoong T, Panich U. Caffeic acid and ferulic acid inhibit UVA-induced matrix metalloproteinase-1 through regulation of antioxidant defense system in keratinocyte $\mathrm{HaCaT}$ cells. Photochem Photobiol 2012;88(4):961-8. doi: 10.1111/j.17511097.2012.01118.x

90. Hahn HJ, Kim KB, Bae S, Choi BG, An S, Ahn KJ, Kim SY. Pretreatment of Ferulic Acid Protects Human Dermal Fibroblasts against Ultraviolet A Irradiation. Ann Dermatol 2016;28(6):740-8.

91. Harwansh RK, Mukherjee PK, Bahadur S, Biswas R. Enhanced permeability of ferulic acid loaded nanoemulsion based gel through skin against UVA mediated oxidative stress. Life Sci 2015;141:202-11. doi: 10.1016/j.lfs.2015.10.001

92. Magnani C, Isaac VLB, Correa MA, Salgadoa HRN. Caffeic Acid: a review of its potential use for medications and cosmetics. Ana Methods 2014; 6(10):3203. doi:10.1039/c3ay41807c

93. Prasad NR, Jeyanthimala K, Ramachandran S. Caffeic acid modulates ultraviolet radiation- $\mathrm{B}$ induced oxidative damage in human blood lymphocytes. J Photochem Photobiol B 2009;95(3):196-203. doi 10.1016/j.jphotobiol.2009.03.007

94. Kang NJ, Lee KW, Shin BJ, Jung SK, Hwang MK, Bode AM, Heo YS, Lee HJ, Dong Z. Caffeic acid, a phenolic phytochemical in coffee, directly inhibits Fyn kinase activity and UVB-induced COX-2 expression. Carcinogenesis 2009;30(2):321-30. doi: 10.1093/carcin/bgn282
95. Staniforth V, Chiu LT, Yang NS. Caffeic acid suppresses UVB radiation-induced expression of interleukin-10 and activation of mitogen-activated protein kinases in mouse. Carcinogenesis 2006;27(9):1803-11.

96. Agilan B, Rajendra Prasad N, Kanimozhi G, Karthikeyan R, Ganesan $M$, Mohana S, Velmurugan D, Ananthakrishnan D. Caffeic Acid Inhibits Chronic UVB-Induced Cellular Proliferation Through JAK-STAT3 Signaling in Mouse Skin. Photochem Photobio 2016;92(3):467-74. doi: 10.1111/php.12588

97. Yamada $Y$, Yasui H, Sakurai H. Suppressive effect of caffeic acid and its derivatives on the generation of UVA-induced reactive oxygen species in the skin of hairless mice and pharmacokinetic analysis on organ distribution of caffeic acid in ddY mice. Photochem Photobiol 2006;82(6):1668-7.

98. Adisakwattana S. Cinnamic Acid and Its Derivatives: Mechanisms for Prevention and Management of Diabetes and Its Complications. Nutrients 2017;9(2). pii: E163. doi: 10.3390/nu9020163

99. Hseu YC, Korivi M, Lin FY, Li ML, Lin RW, Wu JJ, Yang HL. Transcinnamic acid attenuates UVA-induced photoaging through inhibition of AP-1 activation and induction of Nrf2-mediated antioxidant genes in human skin fibroblasts. J Dermatol Sci 2018;90(2):123-134. doi: 10.1016/j.jdermsci.2018.01.004

100. Kong YH, Jo YO, Cho CW, Son D, Park S, Rho J, Choi SY. Inhibitory effects of cinnamic acid on melanin biosynthesis in skin. Biol Pharm Bull 2008;31(5):946-8.

101. Petersen M, Simmonds MS. Rosmarinic acid. Phytochemistry 2003;62(2):121-5.

102. Petersen $M$, Abdullah $Y$, Benner J, Eberle $D$, Gehlen $K$, Hücherig $S$, Janiak V, Kim KH, Sander M, Weitzel C, Wolters S. Evolution of rosmarinic acid biosynthesis. Phytochemistry 2009;70(15-16):1663-79. doi: 10.1016/j.phytochem.2009.05.010

103. Vostálová J, Zdařilová A, Svobodová A. Prunella vulgaris extract and rosmarinic acid prevent UVB-induced DNA damage and oxidative stress in HaCaT keratinocytes. Arch Dermatol Res 2010;302(3):17181. doi: 10.1007/s00403-009-0999-6

104. Lembo S, Balato A, Di Caprio R, Cirillo T, Giannini V, Gasparri F, Monfrecola G. The modulatory effect of ellagic acid and rosmarinic acid on ultraviolet-B-induced cytokine/chemokine gene expression in skin keratinocyte $(\mathrm{HaCaT})$ cells. Biomed Res Int 2014;2014:346793. doi: 10.1155/2014/346793

105. Fernando PM, Piao MJ, Kang KA, Ryu YS, Hewage SR, Chae SW, Hyun JW. Rosmarinic Acid Attenuates Cell Damage against UVB Radiation-Induced Oxidative Stress via Enhancing Antioxidant Effects in Human HaCaT Cells. Biomol Ther (Seoul) 2016;24(1):7584. doi: 10.4062/biomolther.2015.069

106. Sánchez-Campillo M, Gabaldon JA, Castillo J, Benavente-García O, Del Baño MJ, Alcaraz M, Vicente V, Alvarez N, Lozano JA. Rosmarinic acid, a photo-protective agent against UV and other ionizing radiations. Food Chem Toxicol 2009;47(2):386-92. doi: 10.1016/j. fct.2008.11.026

107. Psotová J, Svobodová A, Kolářová H, Walterová D. Photoprotective properties of Prunella vulgaris and rosmarinic acid on human keratinocytes. J Photochem Photobiol B 2006;84(3):167-74.

108. Salehi B, Stojanović-Radić Z, Matejić J, Sharifi-Rad M, Anil Kumar NV, Martins N, Sharifi-Rad J. The therapeutic potential of curcumin: A review of clinical trials. Eur J Med Chem 2019;163:527-45. doi: 10.1016/j.ejmech.2018.12.016

109. Hwang BM, Noh EM, Kim JS, Kim JM, You YO, Hwang JK, Kwon KB, Lee YR. Curcumin inhibits UVB-induced matrix metalloproteinase-1/3 expression by suppressing the MAPK-p38/JNK pathways in human dermal fibroblasts. Exp Dermatol 2013;22(5):371-4. doi: 10.1111/exd.12137

110. Tsai KD, Lin JC, Yang SM, Tseng MJ, Hsu JD, Lee YJ, Cherng JM. Curcumin Protects against UVB-Induced Skin Cancers in SKH-1 Hairless Mouse: Analysis of Early Molecular Markers in Carcinogenesis. Evid Based Complement Alternat Med 2012;2012:593952. doi: 10.1155/2012/593952

111. Liu X, Zhang R, Shi H, Li X, Li Y, Taha A, Xu C. Protective effect of curcumin against ultraviolet $A$ irradiation-induced photoaging in human dermal fibroblasts. Mol Med Rep 2018;17(5):7227-37. doi: 10.3892/mmr.2018.8791

112. Andres S, Pevny S, Ziegenhagen R, Bakhiya N, Schäfer B, HirschErnst KI, Lampen A. Safety Aspects of the Use of Quercetin as a 
Dietary Supplement. Mol Nutr Food Res 2018;62(1). doi: 10.1002/ mnfr.201700447

113. Anand David AV, Arulmoli R, Parasuraman S. Overviews of biological importamce of quercetin: A bioactive flavonoid. Pharmacogn Rev 2016;10(20):84-9. doi: 10.4103/0973-7847.194044

114. Zhu X, Li N, Wang Y, Ding L, Chen H, Yu Y, Shi X. Protective effects of quercetin on UVB irradiation-induced cytotoxicity through ROS clearance in keratinocyte cells. Oncol Rep 2017;37(1):209-218. doi: 10.3892/or.2016.5217

115. Casagrande R, Georgetti SR, Verri WA Jr, Dorta DJ, dos Santos AC, Fonseca MJ. Protective effect of topical formulations containing quercetin against UVB-induced oxidative stress in hairless mice. $J$ Photochem Photobiol B 2006;84(1):21-7.

116. Vicentini FT, Simi TR, Del Ciampo JO, Wolga NO, Pitol DL, lyomasa MM, Bentley MV, Fonseca MJ. Quercetin in w/o microemulsion: in vitro and in vivo skin penetration and efficacy against UVBinduced skin damages evaluated in vivo. Eur J Pharm Biopharm 2008;69(3):948-57. doi: 10.1016/j.ejpb.2008.01.012

117. Kimura S, Warabi E, Yanagawa T, Ma D, Itoh K, Ishii Y, Kawachi $Y$, Ishii T. Essential role of Nrf2 in keratinocyte protection from UVA by quercetin. Biochem Biophys Res Commun 2009;387(1):109-14. doi: 10.1016/j.bbrc.2009.06.136

118. Yeh SL, Wang WY, Huang CH, Hu ML. Pro-oxidative effect of betacarotene and the interaction with flavonoids on UVA-induced DNA strand breaks in mouse fibroblast C3H10T1/2 cells. J Nutr Biochem 2005;16(12):729-35.

119. Sim GS1, Lee BC, Cho HS, Lee JW, Kim JH, Lee DH, Kim JH, Pyo HB, Moon DC, Oh KW, Yun YP, Hong JT. Structure activity relationship of antioxidative property of flavonoids and inhibitory effect on matrix metalloproteinase activity in UVA-irradiated human dermal fibroblast. Arch Pharm Res 2007;30(3):290-8.

120. Maini S, Fahlman BM, Krol ES. Flavonols Protect Against UV Radiation-Induced Thymine Dimer Formation in an Artificial Skin Mimic. J Pharm Pharm Sci 2015;18(4):600-15.

121. Erden Inal M, Kahraman A, Köken T. Beneficial effects of quercetin on oxidative stress induced by ultraviolet A. Clin Exp Dermatol 2001;26(6):536-9.

122. Kahraman $A$, Inal ME. Protective effects of quercetin on ultraviolet A light-induced oxidative stress in the blood of rat. J Appl Toxicol 2002;22(5):303-9.

123. Erden Inal M, Kahraman A. The protective effect of flavonol quercetin against ultraviolet a induced oxidative stress in rats. Toxicology 2000;154(1-3):21-9.

124. Scalia S, Mezzena M. Photostabilization effect of quercetin on the UV filter combination, butyl methoxydibenzoylmethane-octyl methoxycinnamate. Photochem Photobiol 2010;86(2):273-8. doi: 10.1111/j.1751-1097.2009.00655.x

125. Fahlman BM, Krol ES.UVA and UVB radiation-induced oxidation products of quercetin. J Photochem Photobiol B 2009;97(3):123-31. doi: 10.1016/j.jphotobiol.2009.08.009

126. Rajnochová Svobodová A, Ryšavá A, Psotová M, Kosina P, Zálešák $B$, Ulrichová J, Vostálová J. The Phototoxic Potential of the Flavonoids, Taxifolin and Quercetin. Photochem Photobiol 2017;93(5):1240-7. doi: $10.1111 /$ php. 12755

127. Shukla S, Gupta S. Apigenin: a promising molecule for cancer prevention. Pharm Res 2010;27(6):962-78. doi: 10.1007/s11095-0100089-7

128. Choi S, Youn J, Kim K, Joo da H, Shin S, Lee J, Lee HK, An IS, Kwon $\mathrm{S}$, Youn HJ, Ahn KJ, An S, Cha HJ. Apigenin inhibits UVA-induced cytotoxicity in vitro and prevents signs of skin aging in vivo. Int J Mol Med 2016;38(2):627-34. doi: 10.3892/ijmm.2016.2626

129. Britto SM, Shanthakumari D, Agilan B, Radhiga T, Kanimozhi G, Prasad NR. Apigenin prevents ultraviolet- $B$ radiation induced cyclobutane pyrimidine dimers formation in human dermal fibroblasts. Mutat Res 2017;821:28-35. doi: 10.1016/j.mrgentox.2017.06.002

130. Hwang YP, Oh KN, Yun HJ, Jeong HG. The flavonoids apigenin and luteolin suppress ultraviolet A-induced matrix metalloproteinase-1 expression via MAPKs and AP-1-dependent signaling in HaCaT cells. J Dermatol Sci 2011;61(1):23-31. doi: 10.1016/j.jdermsci.2010.10.016

131. Freitas JV, Gaspar LR. In vitro photosafety and efficacy screening of apigenin, chrysin and beta-carotene for UVA and VIS protection. Eur J Pharm Sci 2016;89:146-53. doi: 10.1016/j.ejps.2016.04.032
132. Nabavi SF, Braidy N, Gortzi O, Sobarzo-Sanchez E, Daglia M, SkalickaWoźniak K, Nabavi SM. Luteolin as an anti-inflammatory and neuroprotective agent: A brief review. Brain Res Bull 2015;119(Pt A):1-11. doi: 10.1016/j.brainresbull.2015.09.002

133. Yan M, Liu Z, Yang H, Li C, Chen H, Liu Y, Zhao M, Zhu Y. Luteolin decreases the UVA-induced autophagy of human skin fibroblasts by scavenging ROS. Mol Med Rep 2016;14(3):1986-92. doi: 10.3892/ $\mathrm{mmr} .2016 .5517$

134. Ganeshpurkar A, Saluja AK. The Pharmacological Potential of Rutin. Saudi Pharm J 2017;25(2):149-164. doi: 10.1016/j.jsps.2016.04.025

135. Choi SJ, Lee SN, Kim K, Joo da H, Shin S, Lee J, Lee HK, Kim J, Kwon SB, Kim MJ, Ahn KJ, An IS, An S, Cha HJ. Biological effects of rutin on skin aging. Int J Mol Med 2016;38(1):357-63. doi: 10.3892/ ijmm.2016.2604

136. Gęgotek A, Domingues P, Skrzydlewska E. Proteins involved in the antioxidant and inflammatory response in rutin-treated human skin fibroblasts exposed to UVA or UVB irradiation. J Dermatol Sci 2018;90(3):241-52. doi: 10.1016/j.jdermsci.2018.02.002

137. Dobrzyńska I, Gęgotek A, Gajko E, Skrzydlewska E, Figaszewski ZA. Effects of rutin on the physicochemical properties of skin fibroblasts membrane disruption following UV radiation. Chem Biol Interact 2018;282:29-35. doi: 10.1016/j.cbi.2018.01.012

138. Gegotek A, Rybałtowska-Kawałko P, Skrzydlewska E. Rutin as a Mediator of Lipid Metabolism and Cellular Signaling Pathways Interactions in Fibroblasts Altered by UVA and UVB Radiation. Oxid Med Cell Longev 2017;2017:4721352. doi: 10.1155/2017/4721352

139. Gęgotek A, Ambrożewicz E, Jastrząb A, Jarocka-Karpowicz I, Skrzydlewska E. Rutin and ascorbic acid cooperation in antioxidant and antiapoptotic effect on human skin keratinocytes and fibroblasts exposed to UVA and UVB radiation. Arch Dermatol Res 2019;311(3):203-19. doi: 10.1007/s00403-019-01898-w

140. Gęgotek A, Bielawska K, Biernacki M, Dobrzyńska I, Skrzydlewska E. Time-dependent effect of rutin on skin fibroblasts membrane disruption following UV radiation. Redox Biol 2017;12:733-44. doi: 10.1016/j.redox.2017.04.014

141. Mani R, Natesan V. Chrysin: Sources, beneficial pharmacological activities, and molecular mechanism of action. Phytochemistry 2018;145:187-96. doi: 10.1016/j.phytochem.2017.09.016

142. Kasala ER, Bodduluru LN, Madana RM, V AK, Gogoi R, Barua CC. Chemopreventive and therapeutic potential of chrysin in cancer: mechanistic perspectives. Toxicol Lett 2015;233(2):214-25. doi: 10.1016/j.toxlet.2015.01.008

143. Wu NL, Fang JY, Chen M, Wu CJ, Huang CC, Hung CF. Chrysin protects epidermal keratinocytes from UVA- and UVB-induced damage. J Agric Food Chem 2011;59(15):8391-400.

144. Li H, Li Q, Liu Z, Yang K, Chen Z, Cheng Q, Wu L. The Versatile Effects of Dihydromyricetin in Health. Evid Based Complement Alternat Med 2017;2017:1053617. doi: 10.1155/2017/1053617

145. Moon NR, Kang S, Park S. Consumption of ellagic acid and dihydromyricetin synergistically protects against UV-B induced photoaging, possibly by activating both TGF- $\beta 1$ and wnt signaling pathways. J Photochem Photobiol B 2018;178:92-100. doi: 10.1016/j.jphotobiol.2017.11.004

146. He Z, Zhang L, Zhuo C, Jin F, Wang Y. Apoptosis inhibition effect of Dihydromyricetin against UVA-exposed human keratinocyte cell line. J Photochem Photobiol B 2016;161:40-9. doi: 10.1016/j.jphotobiol.2016.05.002

147. Irrera N, Pizzino G, D'Anna R, Vaccaro M, Arcoraci V, Squadrito F, Altavilla D, Bitto A. Dietary Management of Skin Health: The Role of Genistein. Nutrients 2017;9(6). pii: E622. doi: 10.3390/nu9060622

148. Wei H, Zhang X, Wang Y, Lebwohl M. Inhibition of ultraviolet lightinduced oxidative events in the skin and internal organs of hairless mice by isoflavone genistein. Cancer Lett 2002;185(1):21-9.

149. Shyong EQ, Lu Y, Lazinsky A, Saladi RN, Phelps RG, Austin LM, Lebwohl M, Wei H. Effects of the isoflavone 4,5,7-trihydroxyisoflavone (genistein) on psoralen plus ultraviolet $A$ radiation (PUVA)induced photodamage. Carcinogenesis 2002;23(2):317-21.

150. Garg A, Garg S, Zaneveld LJ, Singla AK. Chemistry and pharmacology of the Citrus bioflavonoid hesperidin. Phytother Res 2001;15(8):655-69.

151. Madduma Hewage SR, Piao MJ, Kang KA, Ryu YS, Han X, Oh MC, Jung U, Kim IG, Hyun JW. Hesperidin Attenuates Ultraviolet B-Induced Apoptosis by Mitigating Oxidative Stress in Human Keratinocytes. Biomol Ther (Seoul) 2016;24(3):312-9. doi: 10.4062/ biomolther.2015.139 
152. Santhanam RK, Fakurazi S, Ahmad S, Abas F, Ismail IS, Rukayadi Y, Akhtar MT, Shaari K. Inhibition of UVB-induced pro-inflammatory cytokines and MMP expression by Zanthoxylum rhetsa bark extract and its active constituent hesperidin. Phytother Res 2018;32(8):1608-16. doi: 10.1002/ptr.6092

153. Petrova A, Davids LM, Rautenbach F, Marnewick JL. Photoprotection by honeybush extracts, hesperidin and mangiferin against UVBinduced skin damage in SKH-1 mice. J Photochem Photobiol B 2011;103(2):126-39. doi: 10.1016/j.jphotobiol.2011.02.020

154. Lee HJ, Im AR, Kim SM, Kang HS, Lee JD, Chae S. The flavonoid hesperidin exerts anti-photoaging effect by downregulating matrix metalloproteinase (MMP)-9 expression via mitogen activated protein kinase (MAPK)-dependent signaling pathways. BMC Complement Altern Med 2018;18(1):39. doi: 10.1186/s12906-0172058-8

155. Li M, Lin XF, Lu J, Zhou BR, Luo D. Hesperidin ameliorates UV radiation-induced skin damage by abrogation of oxidative stress and inflammatory in $\mathrm{HaCaT}$ cells. J Photochem Photobiol B 2016;165:240-5. doi: 10.1016/j.jphotobiol.2016.10.037

156. Olivas-Aguirre FJ, Rodrigo-García J, Martínez-Ruiz ND, CárdenasRobles Al, Mendoza-Díaz SO, Álvarez-Parrilla E, González-Aguilar GA, de la Rosa LA, Ramos-Jiménez A, Wall-Medrano A. Cyanidin3-O-glucoside: Physical-Chemistry, Foodomics and Health Effects. Molecules 2016;21(9). pii: E1264.

157. Tarozzi A, Marchesi A, Hrelia S, Angeloni C, Andrisano V, Fiori J, Cantelli-Forti G, Hrelia P. Protective effects of cyanidin-3-O-betaglucopyranoside against UVA-induced oxidative stress in human keratinocytes. Photochem Photobiol 2005;81(3):623-9.

158. Cimino F, Ambra R, Canali R, Saija A, Virgili F. Effect of cyanidin3-O-glucoside on UVB-induced response in human keratinocytes. J Agric Food Chem 2006;54(11):4041-7.

159. Silván JM, Reguero M, de Pascual-Teresa S. A protective effect of anthocyanins and xanthophylls on UVB-induced damage in retinal pigment epithelial cells. Food Funct 2016;7(2):1067-76. doi: 10.1039/c5fo01368b

160. He Y, Hu Y, Jiang X, Chen T, Ma Y, Wu S, Sun J, Jiao R, Li X, Deng L, Bai W. Cyanidin-3-O-glucoside inhibits the UVB-induced ROS/COX-2 pathway in HaCaT cells. J Photochem Photobiol B 2017;177:24-31. doi: 10.1016/j.jphotobiol.2017.10.006

161. Pratheeshkumar P, Son YO, Wang X, Divya SP, Joseph B, Hitron JA Wang L, Kim D, Yin Y, Roy RV, Lu J, Zhang Z, Wang Y, Shi X. Cyanidin3-glucoside inhibits UVB-induced oxidative damage and inflammation by regulating MAP kinase and NF-KB signaling pathways in SKH-1 hairless mice skin. Toxicol Appl Pharmacol 2014;280(1):12737. doi: 10.1016/j.taap.2014.06.028

162. Liu Z, Hu Y, Li X, Mei Z, Wu S, He Y, Jiang X, Sun J, Xiao J, Deng L, Bai W. Nanoencapsulation of Cyanidin-3- O-glucoside Enhances Protection Against UVB-Induced Epidermal Damage through Regulation of p53-Mediated Apoptosis in Mice. J Agric Food Chem 2018; 66(21):5359-67. doi: 10.1021/acs.jafc.8b01002. y

163. Wu S, Hu Y, Li Z, Bai W, Zhao J, Huang C, Li Q, Fan C, Deng L, Lu D. The effect of Cyanidin-3-o-glucoside on UVA-induced damage in human dermal fibroblasts. Photodermatol Photoimmunol Photomed 2018;34:224-31. doi: 10.1111/phpp.12374

164. Chedea VS, Vicaş SI, Sticozzi C, Pessina F, Frosini M, Maioli E, Valacchi G. Resveratrol: from diet to topical usage. Food Funct 2017;8(11):3879-92. doi: 10.1039/c7fo01086a

165. Athar M, Back JH, Tang X, Kim KH, Kopelovich L, Bickers DR, Kim AL. Resveratrol: a review of preclinical studies for human cancer prevention. Toxicol Appl Pharmacol 2007;224(3):274-83.

166. Chan CM, Huang CH, Li HJ, Hsiao CY, Su CC, Lee PL, Hung CF. Protective effects of resveratrol against UVA-induced damage in ARPE19 cells. Int J Mol Sci 2015;16(3):5789-802. doi: 10.3390/ ijms16035789

167. Liu Y, Chan F, Sun H, Yan J, Fan D, Zhao D, An J, Zhou D. Resveratro protects human keratinocytes $\mathrm{HaCaT}$ cells from UVA-induced oxidative stress damage by downregulating Keap1 expression. Eur J Pharmacol 2011;650(1):130-7. doi: 10.1016/j.ejphar.2010.10.009

168. Hu S, Chen F, Wang M. Photoprotective effects of oxyresveratrol and Kuwanon O on DNA damage induced by UVA in human epidermal keratinocytes. Chem Res Toxicol 2015;28(3):541-8. doi: 10.1021/ tx500497u

169. Boyer JZ, Jandova J, Janda J, Vleugels FR, Elliott DA, Sligh JE. Resveratrol-sensitized UVA induced apoptosis in human keratino- cytes through mitochondrial oxidative stress and pore opening. J Photochem Photobiol B 2012;113:42-50. doi: 10.1016/j.jphotobiol.2012.04.013

170. Seve M, Chimienti F, Devergnas S, Aouffen M, Douki T, Chantegrel J, Cadet J, Favier A. Resveratrol enhances UVA-induced DNA damage in $\mathrm{HaCaT}$ human keratinocytes. Med Chem 2005;1(6):629-33.

171. Pastore S, Lulli D, Pascarella A, Maurelli R, Dellambra E, Potapovich A, Kostyuk V, De Luca C, Korkina L. Resveratrol enhances solar UVinduced responses in normal human epidermal keratinocytes. Photochem Photobiol 2012;88(6):1522-30. doi: 10.1111/j.17511097.2012.01195.x

172. Zeb A. Ellagic acid in suppressing in vivo and in vitro oxidative stresses. Mol Cell Biochem 2018;448(1-2):27-41. doi: 10.1007/ s11010-018-3310-3

173. Hseu YC, Chou CW, Senthil Kumar KJ, Fu KT, Wang HM, Hsu LS, Kuo YH, Wu CR, Chen SC, Yang HL. Ellagic acid protects human keratinocyte (HaCaT) cells against UVA-induced oxidative stress and apoptosis through the upregulation of the $\mathrm{HO}-1$ and $\mathrm{Nrf}-2$ antioxidant genes. Food Chem Toxicol 2012;50(5):1245-55. doi: 10.1016/j. fct.2012.02.020

174. Birtić S, Dussort P, Pierre FX, Bily AC, Roller M. Carnosic acid. Phytochemistry 2015;115:9-19.

175. Park M, Han J, Lee CS, Soo BH, Lim KM, Ha H. Carnosic acid, a phenolic diterpene from rosemary, prevents UV-induced expression of matrix metalloproteinases in human skin fibroblasts and keratinocytes. Exp Dermatol 2013;22(5):336-41. doi: 10.1111/exd.12138

176. Offord EA, Gautier JC, Avanti O, Scaletta C, Runge F, Krämer K, Applegate LA. Photoprotective potential of lycopene, beta-carotene, vitamin $\mathrm{E}$, vitamin $\mathrm{C}$ and carnosic acid in UVA-irradiated human skin fibroblasts. Free Radic Biol Med 2002;32(12):1293-303.

177. Ikeda Y, Murakami A, Ohigashi H. Ursolic acid: an anti- and proinflammatory triterpenoid. Mol Nutr Food Res 2008;52(1):26-42. doi: 10.1002/mnfr.200700389

178. Soo Lee Y, Jin DQ, Beak SM, Lee ES, Kim JA. Inhibition of ultravioletA-modulated signaling pathways by asiatic acid and ursolic acid in HaCaT human keratinocytes. Eur J Pharmacol 2003;476(3):173-8.

179. Nagoor Meeran MF, Goyal SN, Suchal K, Sharma C, Patil CR, Ojha SK. Pharmacological Properties, Molecular Mechanisms, and Pharmaceutical Development of Asiatic Acid: A Pentacyclic Triterpenoid of Therapeutic Promise. Front Pharmacol 2018;9:892. doi: 10.3389/fphar.2018.00892

180. Yuan Y, Zhang H, Sun F, Sun S, Zhu Z, Chai Y. Biopharmaceutical and pharmacokinetic characterization of asiatic acid in Centella asiatica as determined by a sensitive and robust HPLC-MS method. J Ethnopharmacol 2015;163:31-8. doi: 10.1016/j.jep.2015.01.006

181. Bylka W, Znajdek-Awiżeń P, Studzińska-Sroka E, Brzezińska M. Centella asiatica in cosmetology. Postepy Dermatol Alergol 2013;30(1):46-9. doi: 10.5114/pdia.2013.33378

182. Kalantari K, Moniri M, Boroumand Moghaddam A, Abdul Rahim R, Bin Ariff A, Izadiyan Z, Mohamad R. A Review of the Biomedical Applications of Zerumbone and the Techniques for Its Extraction from Ginger Rhizomes. Molecules 2017;22(10). pii: E1645. doi: 10.3390/molecules22101645

183. Murakami A, Tanaka T, Lee JY, Surh YJ, Kim HW, Kawabata K, Nakamura $Y$, Jiwajinda S, Ohigashi $H$. Zerumbone, a sesquiterpene in subtropical ginger, suppresses skin tumor initiation and promotion stages in ICR mice. Int J Cancer 2004;110(4):481-90.

184. Yang HL, Lee CL, Korivi M, Liao JW, Rajendran P, Wu JJ, Hseu YC. Zerumbone protects human skin keratinocytes against UVAirradiated damages through Nrf2 induction. Biochem Pharmacol 2018;148:130-6. doi: 10.1016/j.bcp.2017.12.014

185. Weber D, Grune T. The contribution of $\beta$-carotene to vitamin A supply of humans. Mol Nutr Food Res 2012;56(2):251-8. doi: 10.1002/ mnfr.201100230

186. Stahl W, Sies H. Photoprotection by dietary carotenoids: concept, mechanisms, evidence and future development. Mol Nutr Food Res 2012;56(2):287-95. doi: 10.1002/mnfr.201100232

187. An L, Dong GQ, Gao Q, Zhang Y, Hu LW, Li JH, Liu Y. Effects of UVA on TNF-alpha, IL-1 beta, and IL-10 expression levels in human keratinocytes and intervention studies with an antioxidant and a JNK inhibitor. Photodermatol Photoimmunol Photomed 2010;26(1):2835. doi: 10.1111/j.1600-0781.2009.00481.x

188. Wertz K, Seifert N, Hunziker PB, Riss G, Wyss A, Lankin C, Goralczyk R. Beta-carotene inhibits UVA-induced matrix metalloprotease 1 
and 10 expression in keratinocytes by a singlet oxygen-dependent mechanism. Free Radic Biol Med 2004;37(5):654-70.

189. Wertz K, Hunziker PB, Seifert N, Riss G, Neeb M, Steiner G, Hunziker W, Goralczyk R. beta-Carotene interferes with ultraviolet light A-induced gene expression by multiple pathways. I Invest Dermatol 2005;124(2):428-34.

190. Eicker J, Kürten V, Wild S, Riss G, Goralczyk R, Krutmann J, Berneburg $M$. Beta-carotene supplementation protects from photoaging-associated mitochondrial DNA mutation. Photochem Photobiol Sci 2003;2(6):655-9.

191. Trekli MC, Riss G, Goralczyk R, Tyrrell RM. Beta-carotene suppresses UVA-induced HO-1 gene expression in cultured FEK4. Free Radic Biol Med 2003;34(4):456-64.

192. Obermüller-Jevic UC, Schlegel B, Flaccus A, Biesalski HK. The effect of beta-carotene on the expression of interleukin- 6 and heme oxygenase-1 in UV-irradiated human skin fibroblasts in vitro. FEBS Lett 2001;509(2):186-90.

193. O'Connor I, O'Brien N. Modulation of UVA light-induced oxidative stress by beta-carotene, lutein and astaxanthin in cultured fibroblasts. J Dermatol Sci 1998;16(3):226-30.

194. Camera E, Mastrofrancesco A, Fabbri C, Daubrawa F, Picardo M, Sies $\mathrm{H}$, Stahl W. Astaxanthin, canthaxanthin and beta-carotene differently affect UVA-induced oxidative damage and expression of oxidative stress-responsive enzymes. Exp Dermatol 2009;18(3):222-31. doi: 10.1111/j.1600-0625.2008.00790.x

195. Obermüller-Jevic UC, Francz PI, Frank J, Flaccus A, Biesalski HK Enhancement of the UVA induction of haem oxygenase-1 expression by beta-carotene in human skin fibroblasts. FEBS Lett 1999;460(2):212-6.

196. Zhang G, Zhu B, Nakamura Y, Shimoishi Y, Murata Y. Structuredependent photodegradation of carotenoids accelerated by dimethyl tetrasulfide under UVA irradiation. Biosci Biotechnol Biochem 2008;72(8):2176-83.

197. Davinelli S, Nielsen ME, Scapagnini G. Astaxanthin in Skin Health, Repair, and Disease: A Comprehensive Review. Nutrients 2018;10(4). pii: E522. doi: 10.3390/nu10040522

198. Santocono M, Zurria M, Berrettini M, Fedeli D, Falcioni G. Influence of astaxanthin, zeaxanthin and lutein on DNA damage and repair in UVA-irradiated cells. J Photochem Photobiol B 2006;85(3):205-15

199. Lyons NM, O'Brien NM. Modulatory effects of an algal extract containing astaxanthin on UVA-irradiated cells in culture. J Dermatol Sci 2002;30(1):73-84.

200. Suganuma K, Nakajima H, Ohtsuki M, Imokawa G. Astaxanthin attenuates the UVA-induced up-regulation of matrix-metalloproteinase-1 and skin fibroblast elastase in human dermal fibroblasts. $J$ Dermatol Sci 2010;58(2):136-42. doi: 10.1016/j.jdermsci.2010.02.009

201. Komatsu T, Sasaki S, Manabe Y, Hirata T, Sugawara T. Preventive effect of dietary astaxanthin on UVA-induced skin photoaging in hairless mice. PLoS One 2017;12(2):e0171178. doi: 10.1371/journal. pone. 0171178

202. Stahl W, Heinrich U, Aust O, Tronnier H, Sies H. Lycopene-rich products and dietary photoprotection. Photochem Photobiol Sci 2006;5(2):238-42.

203. Grether-Beck S, Marini A, Jaenicke T, StahI W, Krutmann J. Molecular evidence that oral supplementation with lycopene or lutein protects human skin against ultraviolet radiation: results from a double-blinded, placebo-controlled, crossover study. Br J Dermatol 2017;176(5):1231-40. doi: 10.1111/bjd.15080

204. Yeh SL, Huang CS, Hu ML. Lycopene enhances UVA-induced DNA damage and expression of heme oxygenase- 1 in cultured mouse embryo fibroblasts. Eur J Nutr 2005;44(6):365-70

205. Alves-Rodrigues A, Shao A. The science behind lutein. Toxicol Lett 2004;150(1):57-83.

206. Roberts RL, Green J, Lewis B. Lutein and zeaxanthin in eye and skin health. Clin Dermatol 2009;27(2):195-201. doi: 10.1016/j.clindermatol.2008.01.011

207. Palombo P, Fabrizi G, Ruocco V, Ruocco E, Fluhr J, Roberts R, Morganti P. Beneficial long-term effects of combined oral/topical antioxidant treatment with the carotenoids lutein and zeaxanthin on human skin: a double-blind, placebo-controlled study. Skin Pharmacol Physiol 2007;20(4):199-210.

208. Schwartz S, Frank E, Gierhart D, Simpson P, Frumento R. Zeaxanthinbased dietary supplement and topical serum improve hydration and reduce wrinkle count in female subjects. J Cosmet Dermatol 2016;15(4):e13-e20. doi: 10.1111/jocd.12226

209. Astner S, Wu A, Chen J, Philips N, Rius-Diaz F, Parrado C, Mihm MC, Goukassian DA, Pathak MA, González S. Dietary lutein/zeaxanthin partially reduces photoaging and photocarcinogenesis in chronically UVB-irradiated Skh-1 hairless mice. Skin Pharmacol Physiol 2007;20(6):283-91.

210. Cheah IK, Halliwell B. Ergothioneine; antioxidant potential, physiological function and role in disease. Biochim Biophys Acta 2012;1822(5):784-93. doi: 10.1016/j.bbadis.2011.09.017

211. Obayashi K, Kurihara K, Okano Y, Masaki H, Yarosh DB. L-Ergothioneine scavenges superoxide and singlet oxygen and suppresses TNF-alpha and MMP-1 expression in UV-irradiated human dermal fibroblasts. J Cosmet Sci 2005;56(1):17-27.

212. Hseu YC, Lo HW, Korivi M, Tsai YC, Tang MJ, Yang HL. Dermatoprotective properties of ergothioneine through induction of Nrf2/ ARE-mediated antioxidant genes in UVA-irradiated Human keratinocytes. Free Radic Biol Med 2015;86:102-17. doi: 10.1016/j.freeradbiomed.2015.05.026

213. Bazela K, Solyga-Zurek A, Debowska R, Rogiewicz K, Bartnik E, Eris I. L-Ergothioneine Protects Skin Cells against UV-Induced Damage - Preliminary Study. Cosmetics 2014; 1:51-60; doi:10.3390/cosmetics 1010051 